Canadian

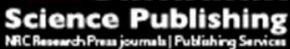

Canadian Geotechnical Journal Revue canadienne de géotechnique

\title{
Performance Assessment of Peat Rail Subgrade Before and After Mass Stabilization
}

\begin{tabular}{|r|l|}
\hline Journal: & Canadian Geotechnical Journal \\
\hline Manuscript ID & cgj-2016-0256.R1 \\
\hline Manuscript Type: & Article \\
\hline Date Submitted by the Author: & $12-$ Oct-2016 \\
\hline Complete List of Authors: & $\begin{array}{l}\text { Wheeler, Lisa; Queen \'s University } \\
\text { Take, W. Andy; Queens University, } \\
\text { Hoult, Neil; Queen's University, Civil Engineering }\end{array}$ \\
\hline Keyword: & railway, track modulus, mass stabilisation, peat, digital image correlation \\
\hline
\end{tabular}

\section{SCHOLARONE ${ }^{\text {m }}$ \\ Manuscripts}


Performance Assessment of Peat Rail Subgrade Before and After Mass Stabilization

\author{
Lisa N Wheeler ${ }^{1}$, W. Andy Take ${ }^{2}$, and Neil A. Hoult ${ }^{3}$
}

\title{
Abstract:
}

Railway tracks over peat subgrades can experience large ground deformations, increased pore water pressures, formation of pumping holes, and pumping of fines during the passage of trains, which can lead to accelerated track deterioration and risk of derailment. One approach to mitigate these issues is to improve the subgrade stiffness using mass stabilization, which involves mixing a binding agent, such as cement, into a soil to improve its physical properties. This paper describes the development and use of a method to calculate trackbed modulus in order to quantify the improvement due to mass stabilization at a site with peat subgrade. Track modulus was calculated using in-service freight trains by measuring track displacements using Digital Image Correlation and wheel loads from a nearby Wheel Impact Load Detector. Because of the voids that existed between the rail, sleepers, and ballast it was found that using displacements of the ballast crib to calculate the trackbed modulus, instead of the overall track modulus using rail or sleeper displacements, provided a way to quantify the improvement of the subgrade that was not affected by the presence of voids. The results indicate the post-rehabilitation trackbed modulus was double the original baseline value for the track section, indicating that mass stabilization can be an effective rehabilitation strategy to improve the stiffness of problematic peat subgrades.

Keywords: railway, track modulus, mass stabilisation, peat, digital image correlation

${ }^{1}$ Research Student, Department of Civil Engineering, Queen's University, Department of Civil Engineering, Kingston, Ontario, Canada, K7L 3N6; E: wheeler.lisa@gmail.com

${ }^{2}$ Corresponding Author: Canada Research Chair in Geotechnical Engineering, Department of Civil Engineering, Queen's University, Department of Civil Engineering, Kingston, Ontario, Canada, K7L 3N6; F: (613) 533-2128, T: (613) 533-3124, E: andy.take@queensu.ca

${ }^{3}$ Associate Professor, Department of Civil Engineering, Queen's University, Department of Civil Engineering, Kingston, Ontario, Canada, K7L 3N6; E: neil.hoult@queensu.ca 


\section{Introduction}

The low subgrade stiffness associated with railway corridors constructed over peat often results

24 in large rail displacements and ground deformations during train passage, leading to accelerated track deterioration and increased risk of derailment due to cyclic pore water pressures, the pumping of fines, and piping hole formation (Figure 1). Typical mitigation strategies for these risks include frequent track maintenance and reduced train speed limits, resulting in increased operating costs and lost productivity for railway owners. Hence, there are considerable financial and risk management incentives to find the most efficient long term remediation techniques for persistent problematic sections of track.

There are a variety of remediation techniques available to improve soft subgrades and they typically focus on improving the subgrade stiffness. For example, the underlying peat can be replaced with a more suitable fill if the problematic peat layers are shallow and thin, however replacement is highly invasive and requires a significant duration of continuous track downtime. Because the financial and operational impacts of track closure are non-linear with time, it is desirable to use a method that can be completed in multiple short blocks of time. One such method is mass stabilization, which is the process of mixing a binding agent, such as Portland cement, fly ash, slag, kiln dust, or lime, into a soil in order to improve its physical properties. One application of mass stabilization is the improvement of the stiffness and bearing capacity of marginal soils, such as peat, beneath both new and existing track (Wilk 2014).

Although mass stabilization can be used to improve a subgrade with minimal impact on rail traffic, it is not known if it provides the same benefits as soil replacement or other traditional subgrade improvement techniques. Visual inspections and records of maintenance frequency may provide an indication of track improvement but quantifying the improvement in terms of increased subgrade stiffness can be challenging. Therefore, developing a method to calculate a localized measure of track quality length of the rail per unit deflection (Selig and Li 1994), and is a function of both the load applied to the rail and the associated track displacement. However, poor subgrade systems are particularly prone to 
50 which further complicates track modulus determination. A method for assessing the improved stiffness 51 must include: a) a method to quantify track behaviour that can account for the presence of voids, b) a 52 measurement of track deflections under dynamic train loading, and c) known wheel loads. The objective 53 of this paper is to develop such a system and to use it to quantify the effectiveness of a mass stabilization 54 field trial.

\section{Background}

Fouled Ballast

Boils in the ballast are problematic in several ways. First, they foul the ballast by transporting fines upwards from the subgrade. Fouled ballast does not drain properly and, once the voids in the ballast become clogged with fines, can result in excess pore pressures being generated during train loading (Tennakoon et al. 2014). The pumping of peat material from the subgrade is also a problem due to the loss of material from beneath the track, which can cause track settlement and poor track geometry. The resulting piping holes can be repaired by filling them with ballast and tamping but have been observed to reappear, sometimes within days. Several methods have been proposed to define the degree of fouling in ballast, including the fouling index method (Selig and Waters 1994), percentage void contamination

65 (Feldman and Nissen 2002), and the relative ballast fouling ratio (Indraratna et al. 2011).

\section{Track Modulus}

The track modulus of a site depends on a number of factors including, but not limited to, the rail type, sleeper type, sleeper spacing, fastener stiffness, as well as the stiffness and thickness of the ballast, subballast, and subgrade. Selig and Li (1994) showed that the subgrade soil condition has the greatest influence on track modulus value. Therefore, comparing the track modulus before and after the mass

71 stabilization should provide a measure of the improvement in subgrade stiffness assuming all other 72 variables remain the same.

The term track modulus was first introduced to railroad engineering using the beam on an elastic

74 foundation (BOEF) model. It is based on Winkler's beam theory (Winkler 1867) and the assumption that

75 the rail responds as a beam supported by a base of closely spaced linear elastic springs. The BOEF 
77 support under each sleeper in the loaded area is constant (Read et al. 1994). The differential equation for 78 a BOEF analysis is:

$79 E I \frac{d^{4} w(x)}{d x^{4}}+u w(x)=q(x)$

80

81

82

83

84

85

86

87

$88 w_{m}=\frac{P \beta}{2 u}$

89

90

91

92

93

94

95

96

97

98

99 load source:

where:

$\boldsymbol{w}(\boldsymbol{x})=$ the vertical deflection of the rail at point $x$ from the applied wheel load,

$\boldsymbol{E}=$ modulus of elasticity for the rail,

$I=$ the second moment of area of the rail,

$\boldsymbol{q}(\boldsymbol{x})=$ the distributed vertical load equivalent to the wheel loads, and

$\boldsymbol{u}=$ the track modulus.

After applying boundary conditions, the equation becomes:

where

$\boldsymbol{w}_{\boldsymbol{m}}=$ the vertical deflection of the rail under the load,

$\boldsymbol{P}=$ the load applied to the rail, and

$$
\beta=\sqrt[4]{\frac{u}{4 E I}}
$$

Equation 2 is only applicable for a single point load on the rail, but applying such a load to a track requires special track loading equipment (e.g. Read et al. 1994). Through the use of superposition, Kerr (1983) developed an equation to calculate track modulus using any available multi-axle rail vehicle as a

$$
w_{m}=\frac{\beta}{2 u} \sum_{i=1}^{n} P_{i} e^{-\beta l_{i}}\left(\cos \beta l_{i}+\sin \beta l_{i}\right)
$$


100

101

102

103

104

105

106

107

108

109

110

$$
\boldsymbol{n}=\text { number of axles, and }
$$

$$
\boldsymbol{l}=\text { the distance between the axle and the point of measured displacement. }
$$

Figure 3 shows theoretical BOEF displacements for a single-axle load as well as a multi-axle load based on the principle of superposition. The BOEF model has the advantage of requiring only a single displacement measurement to calculate track modulus. However, calculating a track modulus based on the displacement at a single location may not be representative of the track response as a whole due to variations in rail, sleeper, ballast, and subgrade conditions.

In order to satisfy vertical equilibrium, the supporting forces on the rail must equal the applied forces. This rail force equilibrium forms the basis of the displacement basin test (DBT) method, which is another method used to calculate track modulus. The DBT method was first proposed by the ASCEAREA Special Committee on Railroad Tracks (Talbot 1980). Track modulus can be found by dividing the sum of the wheel loads by the area of the rail deflection. This is described by the following equation:

$\boldsymbol{u}=\frac{\sum \boldsymbol{P}}{\int_{-\infty}^{\infty} w(x) d x}$

An advantage of this method is that Equation 5 can be used for multi-axle loads even if the spacing of the axle loads is unknown. Also, unlike the BOEF method, the DBT method does not inherently assume that the support under each sleeper in the loaded area is constant (Read et al. 1994). However, in order to determine the displacement basin area the magnitude of rail displacement must be measured at many points along the track, which, depending on the measurement system chosen, can be time consuming and costly. The number of displacement measurements required will depend on both the length of rail that is displaced and the spacing of the measurements, although a measurement spacing equal to the sleeper spacing is sometimes used (e.g. Zarembski and Choros 1980).

\section{Calculation of Track Modulus in the Presence of Voids}

The original definition of track modulus is based on the BOEF model, which assumes that track support remains constant under all load levels, therefore the rails, sleepers, and ballast will be in direct contact when unloaded. Under this assumption, some studies have measured sleeper displacement 
127 instead of rail displacement to calculate track modulus (e.g. Zarembski and Choros 1980; Stewart 1985).

128 However, there can be voids or slack both between the rail and the sleeper as well as between the 129 sleeper and the underlying ballast, which is also known as a hanging sleeper (Figure 2). A void between 130 the rail and the sleeper can be caused by loose spikes; missing and/or defective fasteners; broken, 131 missing, or worn tie plates and pads; concrete sleeper rail seat abrasion; timber sleeper plate cutting; and 132 rotted timber rail seats. Voids between the sleepers and ballast can be the result of cemented ballast 133 conditions or localized differential settlements of the substructure and/or ballast beneath rail joints or in 134 transition zones (Read and Plotkin 2009).

135 Voids within the track superstructure are a complex problem because the magnitude of the voids 136 is usually unknown and can vary greatly from sleeper to sleeper. In addition, the voids located at one 137 sleeper can affect the loads and displacements experienced at adjacent sleepers due to load 138 redistribution (Priest and Powrie 2009). A model by Yang et al. (2009) showed that an unsupported 139 sleeper results in increased stresses in the subballast below neighbouring sleepers, but the effects of an 140 unsupported sleeper rapidly diminish with depth and it is unlikely to have a significant effect on the 141 underlying soil. Because the track displacement at a site with poor quality subgrade is largely driven by 142 the subgrade conditions, it will be assumed that uneven load distribution due to unsupported sleepers will 143 not have a significant impact on the subgrade deformation and stresses.

144 Field measurements have established that vertical track deflections are not proportional to the 145 wheel loads (e.g. Talbot 1980, Zarembski and Choros 1980, Stewart 1985). Kerr and Shenton (1986) 146 suggested that nonlinearity for light wheel loads on poor quality tracks can be attributed to voids between 147 the rails and the sleepers, voids between the sleepers and the ballast, and bending of the sleepers during 148 train loading, whereas nonlinearity for heavy wheel loads on highly maintained track can be attributed to 149 stiffening of the track from compression of the ballast and subgrade layers. For heavy wheel loads on 150 poorly maintained tracks the nonlinearity can be caused by voids in the system and/or stiffening of the 151 ballast and subgrade.

152 When using the BOEF method, track modulus is often calculated based on a typical maximum 153 service load, which means that a stiff track foundation with large voids could have the same track 154 modulus as a soft foundation with no voids. Although the average stiffness for these two cases is 
155 equivalent the behaviour during loading will be different. For example, a track with large voids may 156 experience greater dynamic impact forces due to the closing of the voids, increasing the rate of track 157 deterioration.

An alternate method for calculating track modulus for a track with voids was proposed by the ASCE-AREA Special Committee on Railroad Tracks (Talbot 1980) where the track is loaded with both a

160 light, or seating, load and a heavy, or contact, load and the track displacement is measured for both cases. Using the DBT method, the difference between the areas of the two displacement basins and the

162 difference between the two loads could then be used to calculate a track modulus that describes the 163 ground response and excludes the effect of the voids. However, Kerr and Shenton (1985) questioned the 164 validity of this method for two reasons. The first is the assumption that the seating load removes all slack 165 in the system. Without testing a range of loads the minimum seating load required to remove all slack is 166 not known. In addition, they questioned the validity of the assumption of proportionality between the loads 167 and the reduced area displacement basin.

168 For a track with voids, the rail and sleeper displacement profiles will differ from the theoretical 169 displacement profile of the BOEF model. Previous studies where track modulus was calculated using field measurements with both BOEF and DBT models have typically found the DBT track modulus to be lower

171 than the BOEF track modulus (e.g. Charenko and Scott 1982; Read et al. 1994; Priest and Powrie 2009).

172 Although the definition of track modulus is based on the BOEF model, for a track that does not behave 173 linear elastically the DBT method may be more representative as it captures the actual displacement profile of the track and provides a more conservative estimate of track modulus.

Measurements of rail or sleeper displacement may vary significantly over a short distance due to

177 would exclude the variability due to voids. For example, Mostert and Gräbe (2013) measured both 178 sleeper and ballast displacements at three locations over a span of 10 metres and found that even though 179 the sleeper displacements varied greatly the displacement of the ballast remained relatively constant. 180 This suggests that ballast displacement measurements provide a more consistent measure of the 181 underlying track support stiffness that is independent of voids. However, because the voids are not 182 included, using the ballast displacement to calculate track modulus provides no indication of track quality 
183 with respect to voids. Therefore a track modulus calculated using the ballast crib displacement may be 184 better defined as the trackbed modulus. Although the trackbed modulus is only one factor in the overall 185 track quality, it is a useful parameter to quantify the response of the ballast and subgrade to loading and 186 to determine if a soil rehabilitation technique has been effective.

\section{Strategy for Field Assessment of Track Modulus}

188 The DBT method was chosen as the preferred method for calculating track modulus for several 189 reasons. First, it allows the actual track displacement profile to be used instead of assuming the 190 theoretical BOEF displacement profile. Second, Equation 4 for the BOEF track modulus requires the 191 distances between wheel axles to be known. However, determining these distances for the individual cars

192 of an in-service freight train may be difficult and time-consuming due to the potential variety of cars in a 193 single freight train, therefore providing an advantage to the DBT method. An additional benefit of the DBT 194 method is that the load vs. displacement basin area can be plotted in order to visualize any potential 195 nonlinearity of the track modulus due to increasing loads. The DBT method for calculating track modulus 196 requires a track displacement measurement over the length of the train as well as the corresponding 197 wheel loads.

\section{Track Deflection Measurement}

199 In very poor subgrade soils, such as peat, it is difficult to measure track displacements. In order to 200 provide a constant datum, measurement methods such as potentiometers and extensometers need to be 201 anchored to bedrock, or else sufficiently far below the track surface to be outside of the zone of influence 202 of train loading. Specialized vehicle-mounted measurement systems such as the UNL system (McVey et 203 al. 2005) have limited availability, are costly, and cannot capture settlement of the entire track structure. Digital Image Correlation (DIC) is a non-contact image-based measurement system that can be 205 used to measure track deflections during the passage of a train. DIC determines the change in position of 206 a specified subset of pixels between two-images with sub-pixel accuracy (e.g. White et al. 2003; Take 207 2015). The amount of movement can be converted from pixel space to a physical displacement by 208 applying a scale factor to the data. DIC was first used to measure railway track displacements by 209 Bowness et al. (2006, 2007). Since then, DIC has been used in combination with geophones and/or 
210 accelerometers to study ground deformations (Priest et al. 2010) and transition zones (Coelho et al. 2011;

211 Le Pen et al. 2014), as well as longitudinal rail displacements (Murray et al. 2014).

212 Because the movement of DIC subsets are determined relative to an initial image it is important

213 for the camera to remain stationary during the monitoring process. Any shift in the camera view caused

214 by camera movement would be perceived as a movement of the object being tracked during the DIC

215 analysis, therefore introducing errors into the track displacement measurement. Camera movement

216 induced by ground vibration can occur when using DIC to measure track displacements at sites with poor

217 quality subgrades such as peat (Bowness et al. 2005). In order to account for this movement the two-

218 camera backsight method (Wheeler et al. 2016) was used.

219 Unlike traditional measurement techniques, DIC can be used to measure the displacement of 220 different components of the track by following subsets at different locations in the image. For this study 221 the displacement of the rail, sleepers, and the surface of the ballast crib were measured, which can 222 provide both information about voids in the track and displacement values for track modulus calculation.

223 Figure 4 shows an image used in the DIC analysis and the subset locations. The precision of the DIC 224 measurements was improved by adding visual texture to the subset surfaces by marking them with 225 contrasting spray paint and/or chalk.

226 When DIC is used to measure track displacements the resulting track profile at the monitored 227 location is known with respect to time. In order to calculate track modulus using the DBT method the track 228 displacement profile with respect to distance along the track is required. It is possible to calculate a 229 theoretical track displacement profile by converting the track displacement from time scale to length scale 230 by using either the speed of the train or the axle spacing of the train cars. The method of converting from 231 a time scale to a length scale has previously been used by both Charenko and Scott (1982) and Priest 232 and Powrie (2009). This method assumes that the track conditions at the monitored location are 233 representative of the overall track.

\section{In-service Wheel Loads}

235 A Wheel Impact Load Detector (WILD) is an electronic data collection device consisting of strain 236 gauges installed on both rails over a 15 metre section of track (LB Foster 2015). The strain gauge 237 measurements are used to calculate the vertical wheel force exerted by each wheel at various points as it 
238 rotates through the system. The primary purpose of a WILD is to detect high impact forces caused by 239 damaged wheels, however WILD data has also been useful in providing track loading data (Van Dyk et al. 240 2014).

241 It has been observed that loads produced by moving wheels are greater than those produced by 242 static wheels (e.g. Talbot 1980). The increase in load due to a train's velocity, also known as the dynamic 243 factor, can be caused by impacts due to roll, slip, lurch, shock, buff, torque, load transfer, vibration, and 244 unequal distribution of loads (Hay 1982). In addition, wheels with a higher static load can produce a 245 higher peak dynamic load (Van Dyk et al. 2014). A WILD is able to report both the peak dynamic load and 246 the estimated static load for each wheel.

247 Peat Remediation Site

$248 \quad$ Initial Condition

249 The mass stabilization site is on a single-track railway with timber sleepers and spike fasteners. A 250 typical track cross-section consists of $0.6 \mathrm{~m}$ of ballast, $1.1 \mathrm{~m}$ of sand fill, $1.2 \mathrm{~m}$ of peat, and $0.6 \mathrm{~m}$ of sand 251 underlain by bedrock. The water table sits at or just below the ground surface. The speed limit for this line 252 is $97 \mathrm{~km} / \mathrm{h}(60 \mathrm{mph})$ but restrictions in the remediation area often limited the maximum speed to 16-48 $253 \mathrm{~km} / \mathrm{h}(10-30 \mathrm{mph})$ due to the poor subgrade condition.

The high water table at this site combined with heavy train loading creates excess pore water pressures, resulting in the development of peat boils and piping holes. This mechanism behind the development of boils near railway tracks is discussed in Wong et al. (2006). Figure 5 shows the pumping 257 of material from the subgrade up through the ballast as a train passes a boil over a period of 0.5 seconds.

258 The activation of these peat boils is a function of both the applied load and the loading history.

Figure 6 shows the loads that corresponded to the pumping of fluid and fines during the passage of a single train travelling at approximately $40 \mathrm{~km} / \mathrm{h}(25 \mathrm{mph})$. The pumping events were correlated to the

262 static wheel loads applied to the rail for each bogie. The static wheel loads were obtained from a WILD 263 system located approximately $200 \mathrm{~km}$ east of the monitoring site. Although the train weight data from the 264 WILD was not collected at the remediation site, it was assumed that the loads did not change between the WILD site and the remediation site. 


\section{Mass Stabilization Procedure}

A variety of mixing equipment can be used to perform mass stabilization, such as deep soil mixing augers, high pressure jets, pulver mixers or road reclaimers, power mixer attachments for excavators, and bare excavator buckets (Wilk 2014). The system used at the study site consisted of three parts: a power mixer attachment for an excavator, which injects the binder at the point of mixing; a pressure feeder, which moves the binder from its container, through a hose, and out through the middle of the mixing drums of the power mixer; and the data acquisition control, which controls the amount of binder that is injected (ALLU Finland Ltd. 2015). The system is shown in Figure 7.

The mass stabilization was performed on a $50 \mathrm{~m}$ length of track. In order to complete the remediation with minimal disruption to train traffic, the mass stabilization area was divided into 1.5 metre long panels. The work was sequenced in order to avoid stabilization of adjacent panels on the same day. Remediation of the site was completed in three to four weeks.

As seen in Figure 7c, the ballast at the edge of the track was removed using an excavator, allowing access to the subgrade over the length of the panel. The mass stabilization was performed by inserting the power mixer head into the peat while injecting and mixing the cement binder into the peat subgrade. Mixing was completed from the underlying bedrock to the surface of the peat subgrade, which corresponds to a depth of approximately 1-2 metres. The power mixer was extended beneath the track up to 40 degrees from the edge of the sleepers in order to stabilize a wedge of peat beneath the track. A zone of peat directly beneath the track could not be reached while leaving the track intact and was therefore left unstabilized, however the two wedges of stabilized peat on either side of the rails are assumed to provide support and add stiffness to the unstabilized material.

Train traffic was able to resume once the minimum strength value required by the design engineers was reached for the panels completed that day. After confirming minimum strength via vane testing, the peat was smoothed and compacted by the excavator and the ballast was restored. The track level was then checked, and, if required, track geometry was serviced via tamping.

\section{Instrumentation}

A setup consisting of four cameras was used to monitor track displacement at the remediation site. Using the backsight camera technique (Wheeler et al. 2016), two cameras were setup to monitor the 
294 track while the other two were used as backsight cameras to account for potential camera shake due to

295 vibrations in the soft subgrade. Figure 8 shows the camera setup used in the study as well as the field of

296 view captured by the two foresight cameras. Each foresight camera monitored approximately 0.5 metres

297 of rail, two sleepers, and the surface of the ballast crib between the two sleepers. The cameras were set

298 up to monitor four consecutive sleepers. Metal angles were attached to the sleepers to provide a surface

299 to track for DIC displacement measurement. Ballast crib displacements were found by tracking the

300 displacement of one or two large ballast particles on the surface of the ballast between two sleepers.

301 Train weight data was obtained from the WILD system located approximately $200 \mathrm{~km}$ east of the 302 monitoring site.

303

\section{Quantification of Track Modulus Prior to Stabilization Work}

The ballast was tamped each morning after the mass stabilization panels were completed for the day but before the pre-mass stabilization monitoring began, resulting in significant ballast compaction and settlement during passage of the first train. Therefore, the first train passing the site after tamping was omitted from the study. Three freight trains were monitored over two days before the mass stabilization work began. A list of the monitored trains can be found in Table 1.

\section{Determination of Dynamic Wheel Loads}

The definition of track modulus is based on a static displacement under a static load. Because the track displacements due to static loads are not known, dynamic loads and dynamic displacements were used to calculate track modulus. Since both the pre and post-mass stabilization track modulus will be found using trains travelling at similar speeds it is believed that using dynamic values instead of static values will not have a significant impact on the results on the study results.

During the mass stabilization project, data for a number of trains travelling over the WILD system at different speeds were collected, including the velocity of the train, the peak measured dynamic load, and the estimated static load for each wheel. Using this data, the static loads were plotted against the measured dynamic loads normalized by train speed, which showed that for a given speed and static wheel load, there was a clear minimum dynamic load but the peak dynamic load could vary greatly. It is believed that the majority of the peak dynamic loads are caused by irregularities of the train car, such as 
321 wheel flats or other impacts. In order to avoid overestimating both the dynamic load and the subsequent 322 track modulus, a lower-bound line was empirically fit to the data. The equation for this line is:

$323 \quad \boldsymbol{F}_{\boldsymbol{d}}=\boldsymbol{F}_{\boldsymbol{s}}+\left(\frac{\boldsymbol{F}_{s}}{200}+\mathbf{0 . 1}\right) * \boldsymbol{V}$

where

$\boldsymbol{F}_{\boldsymbol{d}}=$ the dynamic load in $\mathrm{kN}$,

$\boldsymbol{F}_{\boldsymbol{s}}=$ the static load in $\mathrm{kN}$, and

loads based on the speed of the train when it passed the monitoring site, as measured using the high speed camera images. Based on the range of static wheel loads and train speeds at the mass stabilization site the dynamic loads ranged from 5 to $9 \%$ greater than the static loads.

\section{Determination of the Displacement Basin Area}

The full displacement profiles for a rail, sleeper, and the adjacent ballast crib during the passage

335 of Train 2, as well as the calculated dynamic loads for each wheel is shown in Figure 9. The dynamic 336 loads were calculated using Equation 6, the static wheel loads from the WILD data, and the speed of the 337 train as it passed the mass stabilization site. Train 2 was chosen as it exhibits a wide range of loads and 338 axle spacings. Comparing the rail, sleeper, and ballast crib displacements it can be seen that the 339 magnitudes of each are different, which suggests that voids are present at this location. Furthermore, the 340 figure shows that higher wheel loads correspond to greater track displacements.

341 Figure 10 shows the displacement data presented in Figure 9 for the first 4 locomotives and 5 342 cars of the Train 2 as well as the associated dynamic wheel loads. The DBT method is based on ideal 343 track displacement data taken from static measurements, such as the theoretical displacement profile

344 seen in Figure 3. However, Figure 10 illustrates several ways in which the DIC track displacement data 345 varies from an idealized track displacement. These differences include the track not returning to zero 346 displacement between car bogies and upward rail bending. A method to account for these variances was 347 developed in order to both determine the area of the displacement basin and calculate the track modulus. 
In Figure 10 the sleeper and ballast do not always return to zero displacement between the 349 bogies of a car. Potential causes of this behaviour include drainage of excess pore water (e.g. Kerr 2000) 350 and ballast settlement after tamping. These factors have a small impact on the area of the displacement 351 basin over the length of a single car, but if allowed to accumulate over the full length of a train they could 352 result in significant errors. If the displacement basin area is taken as the peak to peak area between car 353 bogies, as seen in Figure 11, any accumulating error due to pore water drainage and ballast settlement will not compound along the length of the train, thereby providing a more consistent track modulus.

Figure 10 also shows the rail experiencing upward displacement due to rail lift-off. If a peak to peak displacement basin is used when there is rail lift-off then the area of the displacement basin will be overestimated. Because the track does not always return to zero displacement between a car's bogies, it is not known when rail lift-off begins; therefore it was assumed to be the point where the rail displacement line crosses above the sleeper displacement line. In order to calculate the rail's displacement basin the rail displacement was replaced with the sleeper displacement for the portion of time that lift-off was occurring, as shown in Figure 11.

\section{Calculation of Track Modulus}

363 Figure 12 plots the displacement basin area for the rail, sleeper, and ballast crib versus the sum 364 of the dynamic wheels loads associated with each displacement basin. There are several observations 365 that can be made about this data. First, there is a greater degree of scatter in the data for the rail (and, to 366 a lesser extent, the sleeper) than there is for the ballast crib. This could be due to the effect of the voids 367 combined with the variation in wheel spacing. For example, in a system with voids, two closely spaced 368 axles will create a different displacement basin area than two axles spaced further apart (i.e. extensive 369 load redistribution). Another observation is that the track modulus values differ for each of the three track 370 components. As expected, due to the presence of voids, the rail has the lowest modulus while the ballast 371 crib has the highest. The rail data appears to follow a nonlinear trend (suggesting a modulus that is 372 dependent on the applied load) whereas the ballast crib data appears to follow a more linear trend.

373 Because the modulus value based on the ballast crib displacement appears to be independent of 374 loading level due to the exclusion of the voids, it was decided that effectiveness of the mass stabilization 375 would be determined using the trackbed modulus. In order to investigate the repeatability of using the 
376 ballast crib displacement, the trackbed modulus for three different trains before mass stabilization was

377 found. Figure 13a, b, and c plot the displacement basin area versus loading for the two ballast crib 378 monitoring locations of the three pre-mass stabilization trains. A similar trackbed modulus is observed at 379 the measurement locations for all three trains and was found to range from 12 to $17 \mathrm{MPa}$. The overall 380 average trackbed modulus is $15 \mathrm{MPa}$.

\section{Post Mass Stabilization Trackbed Modulus}

Following the completion of the mass stabilization work, three additional freight trains were 383 monitored in order to calculate the trackbed modulus for the mass stabilized subgrade. A list of the trains 384 monitored after the mass stabilization is presented in Table 2.

Figure 14 shows the displacement profiles of the rail, sleeper, and the ballast crib, as well as the

386 individual dynamic wheel loads for the beginning of Train 5. Comparing the peak displacements after 387 mass stabilization with the displacements before mass stabilization (Figure 10) it can be seen that the peak displacements for the ballast crib decreased from approximately $4 \mathrm{~mm}$ to $2 \mathrm{~mm}$ for the first

389 locomotive bogie. However, the peak rail and sleeper displacements increased from 7 and $5 \mathrm{~mm}$ to 9 and

$3908 \mathrm{~mm}$, respectively. This suggests that the magnitude of the total void between the rail and ballast 391 increased between the collection of the pre and post-mass stabilization datasets. Therefore, if the track 392 modulus was calculated based on the rail or sleeper displacements, as is common practice, the resulting 393 value would have indicated a decrease in track modulus due to the mass stabilization, possibly 394 suggesting that the mass stabilization did not improve the trackbed stiffness. However, the decrease in 395 the ballast crib displacements verify that the stiffness of the underlying peat increased and the decrease 396 in track modulus is due to an increase in the void magnitude.

397 The reason for the increase in the void size at the monitored location is not known. It is possible 398 that the voids were redistributed amongst the sleepers due to the amount of track disturbance and 399 tamping that occurred during the mass stabilization project (the track was resurfaced after all the panels 400 were stabilized between Monitoring Day 3 and 4). The observation that the voids in the system remained 401 after rehabilitation is a useful reminder that the mass stabilisation mitigation strategy targeted only the 402 stiffness of the peat subgrade and to arrest the peat boil formation process, whilst leaving the rest of the 
403 track structure above this elevation largely untouched. Therefore, addressing other track issues above the

404 elevation of the subgrade such as fouled ballast and the presence of voids would require further 405 rehabilitation work specifically targeting these issues.

Figure $15 a, b$, and $c$ show the areas of the ballast crib displacement basins versus the wheel load

407 for the three trains monitored after mass stabilization. The DIC analysis for the Train 4 image sequence

408 was not able to correctly determine the displacement at certain points during the train's passage due to 409 shadows and cement dust from the mass stabilization affecting the image quality. Therefore only the 410 displacement basins from Location 1 with good quality data were used in the analysis. The trackbed 411 modulus at the measurement locations for all three trains ranged from 37 to $42 \mathrm{MPa}$, with an average of $41239 \mathrm{MPa}$.

413 Figure 16 shows the trackbed modulus calculated at both monitoring locations for the three trains 414 before mass stabilization and the three trains after mass stabilization. The mass stabilization more than 415 doubled the trackbed modulus. As a point of comparison, a minimum track modulus of $28 \mathrm{MPa}$ was 416 suggested by Selig and Li (1994) to ensure satisfactory track performance. Raymond (1985) proposed a 417 minimum track modulus of $35 \mathrm{MPa}$. Both of these values were chosen by plotting the theoretical track 418 modulus versus the displacement for a BOEF model and determining the point where track modulus 419 begins to have a dramatic effect on the track displacement. These recommended minimum values are 420 based on the assumption of a constant track support and no voids. Because the trackbed modulus does 421 not include voids it is reasonable to assume that the trackbed modulus for a good quality site should be 422 above the minimum recommended track modulus values. As such, it appears that the trackbed modulus 423 at the mass stabilization site went from an unacceptable to an acceptable value. However, addressing 424 other track issues above the elevation of the ameliorated subgrade such as fouled ballast and the 425 presence of voids would require further rehabilitation work specifically targeting these issues.

\section{Conclusions}

A rail site with piping holes and peat boils due to a soft peat subgrade and high pore water 
429 conditions. Track modulus was chosen to quantify the effect of the mass stabilization as its value is $430 \quad$ largely driven by the subgrade conditions.

431 A method for calculating track modulus was developed in order to quantify the ground 432 improvement at the site. Rail, sleeper, and ballast crib displacements were measured using DIC, and 433 wheel loads were determined using WILD data. An advantage to this method is that track modulus can be 434 calculated using in-service freight trains, allowing for measurement of a wide range of loads and axle configurations. Track modulus was calculated using the DBT method for rail and sleeper displacements,

436 but it was decided that the trackbed modulus, calculated using the ballast crib displacements, provided 437 the best measure of improvement due to the mass stabilization because it was consistent for all loading 438 levels and did not appear to be influenced by the presence of voids.

Three trains were monitored both before the mass stabilization and 10-40 days after the mass

441 that the mass stabilization was successful at increasing the trackbed modulus from a value of $15 \mathrm{MPa}$ to $44239 \mathrm{MPa}$. Comparing this to the minimum recommended track modulus value of $28 \mathrm{MPa}$ by Selig and $\mathrm{Li}$ 443 (1994), it appears that the trackbed modulus was increased to an acceptable value. Furthermore, to date 444 no additional peat boils have been observed on the rehabilitated track after mass stabilisation. However, 445 the observation that the voids in the system remained after rehabilitation is a useful reminder that the 446 mass stabilisation mitigation strategy targeted only the stiffness of the peat subgrade and to arrest the 447 peat boil formation process whilst leaving the rest of the track structure above this elevation largely 448 untouched. Therefore, addressing other track issues above the elevation of the subgrade such as fouled 449 ballast and the presence of voids would require further rehabilitation work specifically targeting these 450 issues.

\section{Acknowledgements}

452 This study was financially supported by the Natural Sciences and Engineering Research Council 453 of Canada (NSERC) under the Discovery, and Research Tools and Instruments programs and by Golder 454 Associates through the Golder Fellowship program. The Authors are grateful for the valuable assistance 
455 of Dr Graeme Skinner and Dr Paul Dittrich of Golder Associates in conducting the field validation and 456 monitoring experiments. 


\section{References}

ALLU Finland Ltd. 2015. Stabilisation System. http://www.allu.net/products/stabilisation-system

Bowness, D., Lock, A.C., Richards, D.J., and Powrie, W. 2006. Innovative remote video monitoring of railway track displacements. Applied Mechanics and Materials, 3: 417-422. doi:10.4028/www.scientific.net/AMM.3-4.417

Bowness, D., Lock, A.C., Powrie, W., Priest, J.A., and Richards, D.J. 2007. Proceedings of the Institution of Mechanical Engineers, Part F: Journal of Rail and Rapid Transit, 221(1): 13-22.

Charenko, A., and Scott, J. F. 1982. The measurement of track modulus. Track Structures Test Facility Progress Report No. 5. CN Rail Research Centre, St. Laurent, Quebec.

Coelho, B., Hölscher, P., Priest, J., Powrie, W., and Barends, F. 2011. An assessment of transition zone performance. Proceedings of the Institution of Mechanical Engineers, Part F: Journal of Rail and Rapid Transit, 225(2): 129-139.

Crawford, S., Murray, M., and Powell, J. 2001. Development of a mechanistic model for the determination of track modulus. In Proceedings $7^{\text {th }}$ International Heavy Haul Conference, Brisbane, Australia.

Feldman, F., and Nissen, D. 2002. Alternative testing method for the measurement of ballast fouling: percentage void contamination. In Proceedings of CORE 2002: Cost Efficient Railways through Engineering, Wollongong, Australia.

Hay, W.W. 1982. Railroad Engineering. $2^{\text {nd }}$ ed. John Wiley \& Sons.

Indraratna, B., Su, L.J., and Rujikiatkamjorn, C. 2011. A new parameter for classification and evaluation of railway ballast fouling. Canadian Geotechnical Journal, 48(2): 322-326.

Kerr, A.D. 1983. A method for determining the track modulus using a locomotive or car on multi-axle trucks. In Proceedings AREA, 84: 269-286.

Kerr, A.D. 2000. On the determination of the rail support modulus $k$. International Journal of Solids and Structures, 37(32): 4335-4351.

Kerr, A.D., and Shenton III, H.W. 1985. On the reduced area method for calculating the vertical track modulus. In Proceedings AREA, 86: 416-429.

Kerr, A.D., and Shenton III, H.W. 1986. Railroad track analyses and determination of parameters. In Proceedings ASCE, Journal of Engineering Mechanics, 112(11): 1127-1134.

LB Foster 2015. Wheel Impact Load Detector (WILD). http://www.Ibfostersalientsystems.com/Wheel_Impact_Load_Detector.asp

Le Pen, L., Watson, G., Powrie, W., Yeo, G., Weston, P., and Roberts, C. 2014. The behaviour of railway level crossings: Insights through field monitoring. Transportation Geotechnics, 1(4): 201-213.

McVey, B., Norman, C., Wood, N., Farritor, S., Arnold, R., Fateh, M., and El-Sibaie, M. 2005. Track modulus measurement from a moving railcar. In Proceedings of the AREMA Annual Conference, Chicago, IL.

Mostert, L., and Gräbe, H. 2013. The development of a simplified track modulus calculation procedure. Civil Engineering (Siviele Ingenieurswese), 21(4): 22-28. 
Murray, C.A., Take, W.A., and Hoult, N.A. 2014. Measurement of vertical and longitudinal rail displacements using digital image correlation. Canadian Geotechnical Journal, 52(2): 141-155.

Priest, J.A., and Powrie, W. 2009. Determination of dynamic track modulus from measurement of track velocity during train passage. Journal of Geotechnical and Geoenvironmental Engineering, 135(11): 1732-1740.

Priest, J.A., Powrie, W., Yang, L., Grabe, P.J., and Clayton, C.R.I. 2010. Measurements of transient ground movements below a ballasted railway line. Géotechnique, 60(9): 667-677.

Raymond, G.P. 1985. Analysis of track support and determination of track modulus. Transportation Research Record, 1022: 80-90.

Read, D. M., and Plotkin, D. 2009. Issues surrounding the measurement and application of vertical track stiffness data. In Proceedings of the 2009 ASME Joint Rail Conference, Pueblo, Colorado, 3-5 March, 2009.

Read, D., Chrismer, S., Ebersöhn, W., and Selig, E. 1994. Track modulus measurements at the Pueblo soft subgrade site. Transportation Research Record, 1470: 55-64.

Selig, E.T., and Li, D. 1994. Track modulus: Its meaning and factors influencing it. Transportation Research Record, 1470: 47-54.

Selig, E.T., and Waters, J.M. 1994. Track geotechnology and substructure management. Thomas Telford Services Ltd., London.

Stewart, H. E. 1985. Measurement and prediction of vertical track modulus. Transportation Research Record, 1022: 65-71.

Take, W.A. 2015. Thirty-Sixth Canadian Geotechnical Colloquium: Advances in visualization of geotechnical processes through digital image correlation. Canadian Geotechnical Journal, 52(9): 1199-1220.

Talbot A.N. 1980. Stresses in Railroad Track - The Talbot Reports. AREA.

Tennakoon, N., Indraratna, B., and Rujikiatkamjorn, C. 2014. Effect of ballast contamination on the behaviour of track substructure. Australian Geomechanics Journal, 49(4): 113-123.

Van Dyk, B.J., Dersch, M.S., Edwards, J.R., Ruppert Jr., C.J., and Barkan, C.P.L. 2014. Load characterization techniques and overview of loading environment in North America. Journal of the Transportation Research Board, 2448: 80-86.

Wheeler, L.N., Take, W.A., and Hoult, N.A. 2016. Measurement of rail deflection on soft subgrades using DIC. Proceedings of the Institution of Civil Engineers - Geotechnical Engineering, DOI: 10.1680/jgeen.15.00171.

White, D.J., Take, W.A., and Bolton, M.D. 2003. Soil deformation measurement using particle image velocimetry (PIV) and photogrammetry. Geotechnique, 53(7): 619-631.

Wilk, C.M. 2014. Stabilization of marginal soil in new and existing right-of-way. In Proceedings of the AREMA 2014 Annual Conference \& Exposition. Chicago, Illinois.

Winkler, E. 1867. Die lehre von der elasticität und festigkeit. H. Dominicus, Prag. Section 195. 
Wong, R.C.K., Thomson, P.R., and Choi, E.S.C. 2006. In situ pore pressure responses of native peat and soil under train load: a case study. Journal of Geotechnical and Geoenvironmental Engineering, 132(10): 1360-1369.

Yang, L. A., Powrie, W., and Priest, J. A. 2009. Dynamic stress analysis of a ballasted railway track bed during train passage. Journal of Geotechnical and Geoenvironmental Engineering, 135(5): 680689.

Zarembski, A. M., and Choros, J. 1980. On the measurement and calculation of vertical track modulus. In Proceedings AREA, 81: 156-173. 


\section{Figure Captions}

Figure 1. a) Boils and b) voids in the track ballast

Figure 2. Potential voids in the rail superstructure

Figure 3. Theoretical Beam on Elastic Foundation displacement for a single-axle load and a multi-axle load

Figure 4. Example of subsets used for DIC analysis

Figure 5. Image sequence illustrating the pumping and ejection of fluid and fines during the passage of a train

Figure 6. Bogie loads which resulted in active pumping and ejection of fluids and fines

Figure 7. a) Mass stabilization system, b) power mixer head, c) ballast removed for mixing, and d) mixing cement into peat subgrade

Figure 8. Camera setup

Figure 9. Vertical displacement for full train for a) rail, b) sleeper, c) ballast, and d) associated wheel loads

Figure 10. Rail, sleeper, and ballast crib displacement and the associated wheel loads at the beginning of a train before mass stabilization showing a) the difference in rail, sleeper, and ballast crib displacements, b) the sleeper and ballast crib not returning to zero displacement under rail car centers, and c) upward rail bending

Figure 11. Sample areas used for displacement basin track modulus calculation for a) rail, b) sleeper, and c) ballast crib

Figure 12. Displacement basin area versus dynamic load for the rail, sleeper, and ballast crib for Train 2

Figure 13. Pre-mass stabilization ballast crib displacement basin area versus dynamic load for a) Train 1, b) Train 2, and c) Train 3

Figure 14. Rail, sleeper, and ballast crib displacement and the associated wheel loads at the beginning of a train after mass stabilization

Figure 15. Post-mass stabilization ballast crib displacement basin area versus dynamic load for a) Train 4, b) Train 5, and c) Train 6

Figure 16. Comparison of track modulus pre- and post-mass stabilization 


\section{Tables}

Table 1. Summary of trains monitored before mass stabilization

\begin{tabular}{|c|c|c|c|c|}
\hline Train & Monitoring Day & Number of Engines & Number of Freight Cars & Speed km/h (mph) \\
\hline 1 & 1 & 2 & 58 & $39(24)$ \\
\hline 2 & 2 & 4 & 111 & $39(25)$ \\
\hline 3 & 2 & 2 & 129 & $32(20)$ \\
\hline
\end{tabular}

Table 2. Summary of trains monitored after mass stabilization

\begin{tabular}{|c|c|c|c|c|c|}
\hline Train & Monitoring Day & $\begin{array}{c}\text { Days After Mass } \\
\text { Stabilization }\end{array}$ & $\begin{array}{c}\text { Number of } \\
\text { Engines }\end{array}$ & $\begin{array}{c}\text { Number of Freight } \\
\text { Cars }\end{array}$ & $\begin{array}{c}\text { Speed } \mathrm{km} / \mathrm{h} \\
(\mathrm{mph})\end{array}$ \\
\hline 4 & 3 & 10 days & 2 & 99 & $38(23)$ \\
\hline 5 & 4 & 40 days & 1 & 80 & $35(22)$ \\
\hline 6 & 4 & 40 days & 2 & 143 & $43(27)$ \\
\hline
\end{tabular}


a)

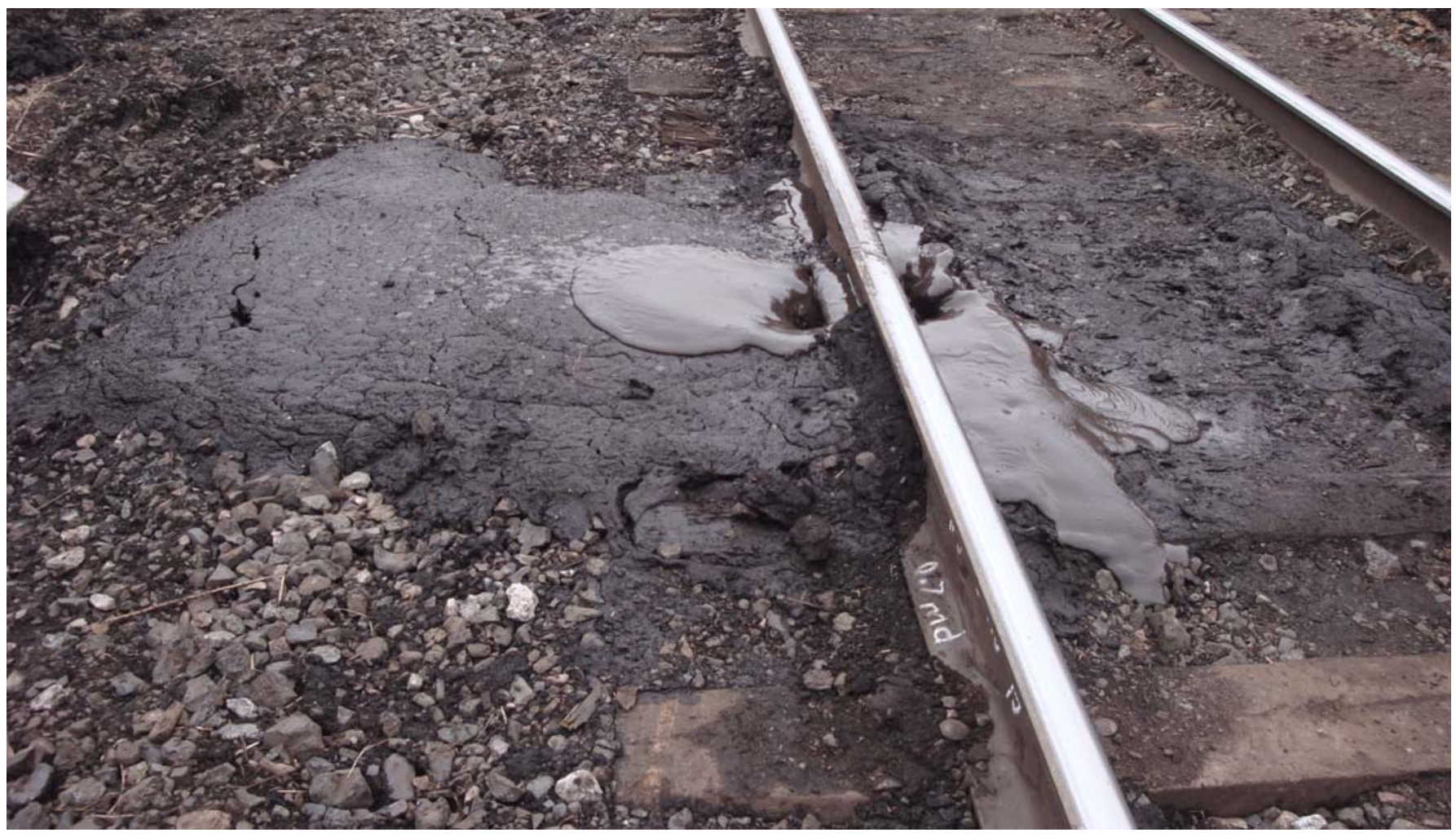

b)

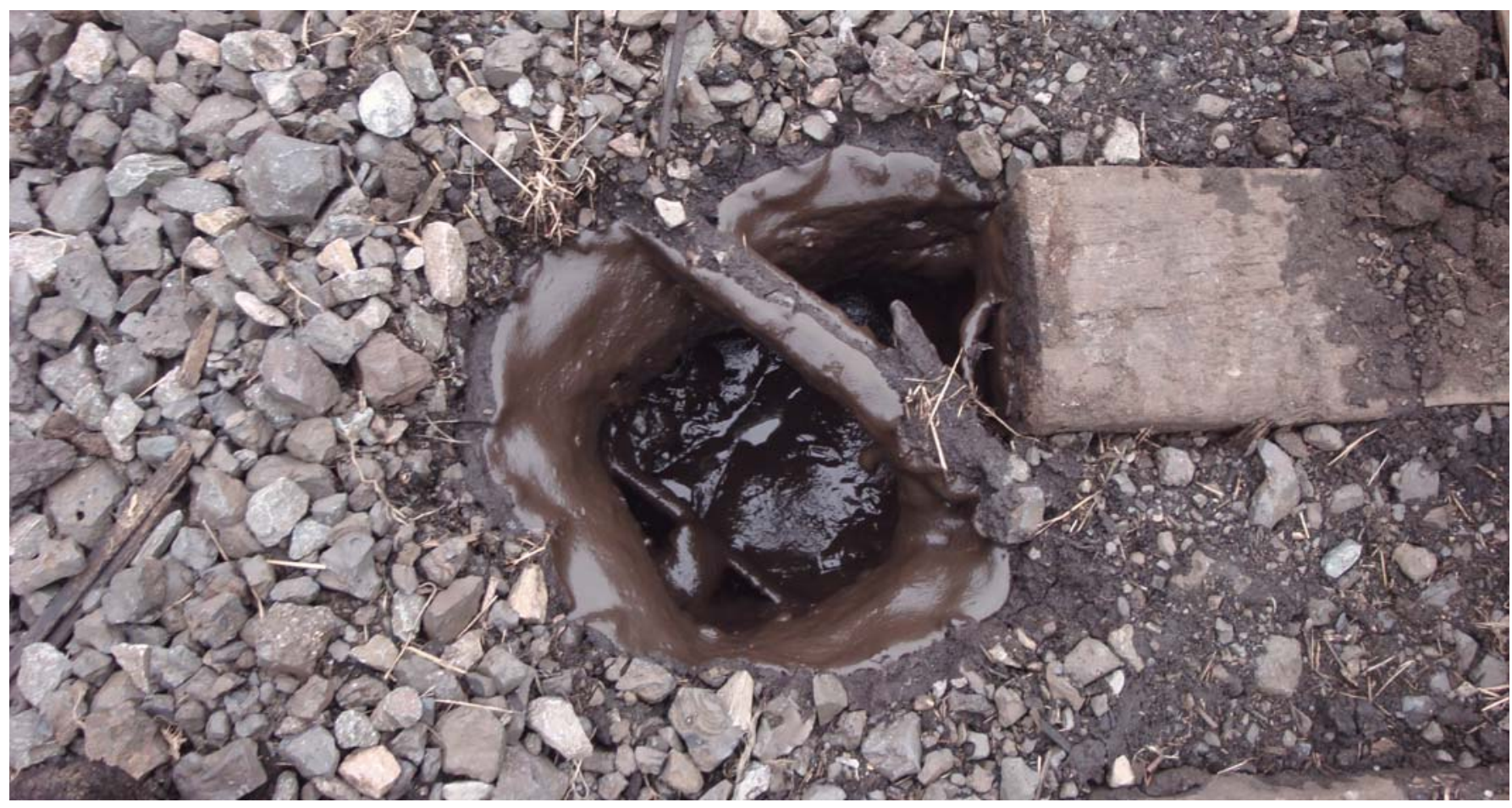

Figure 1. a ) Boils and b ) piping holes in the track ballast 


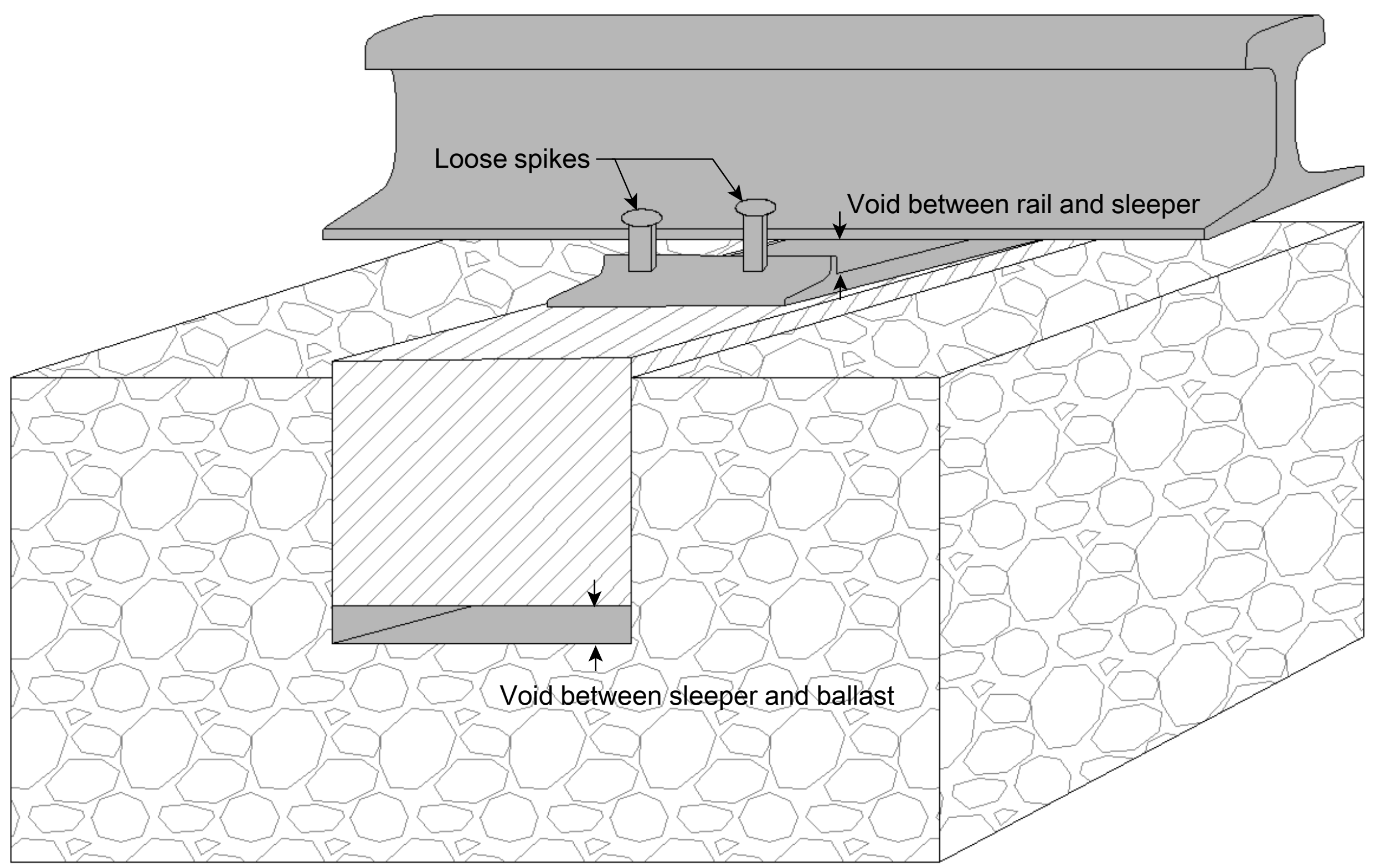

Figure 2. Potential voids between the rail, sleeper, and ballast 


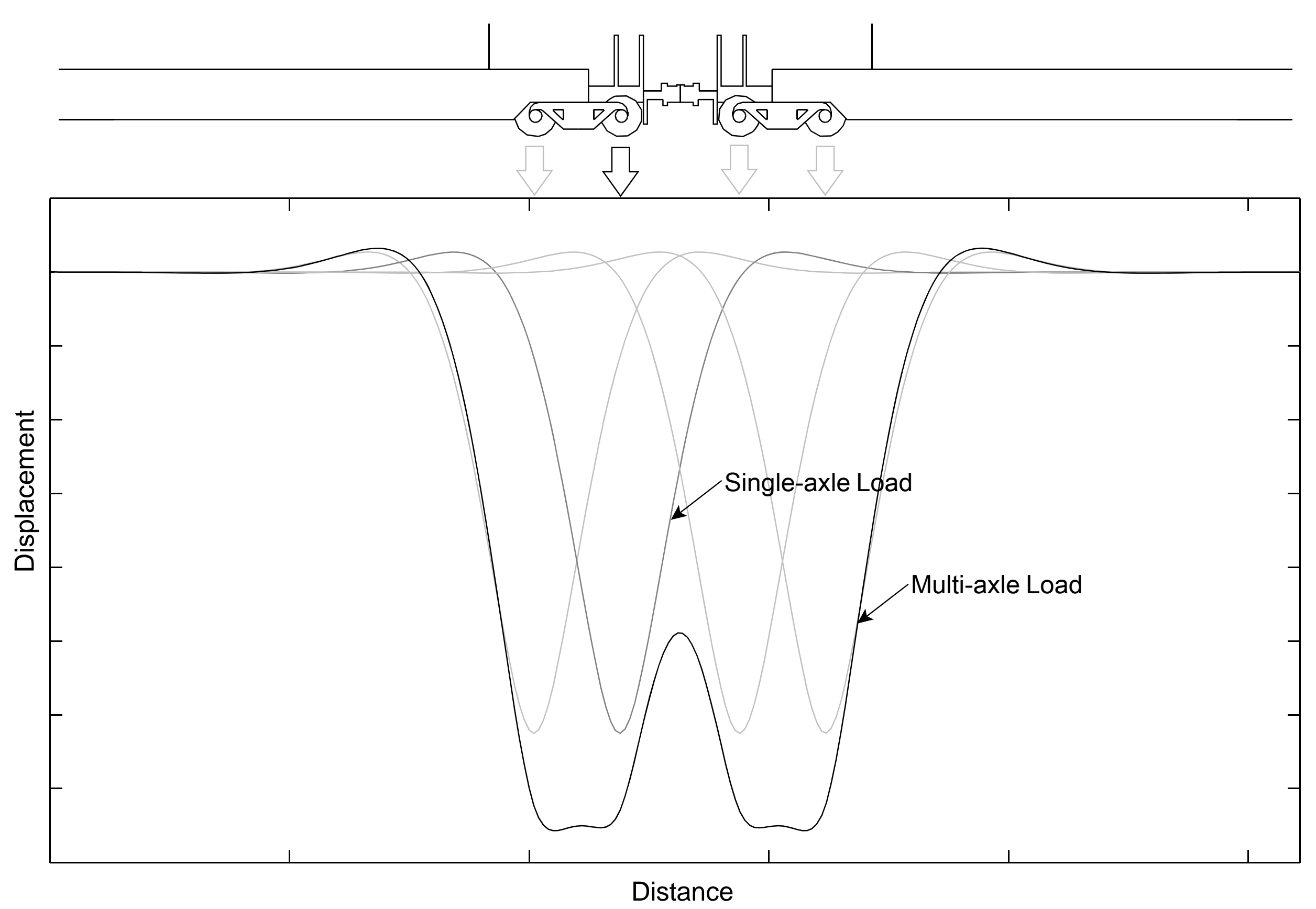

Figure 3. Theoretical Beam on Elastic Foundation displacement for a single-axle load and a multi-axle load 


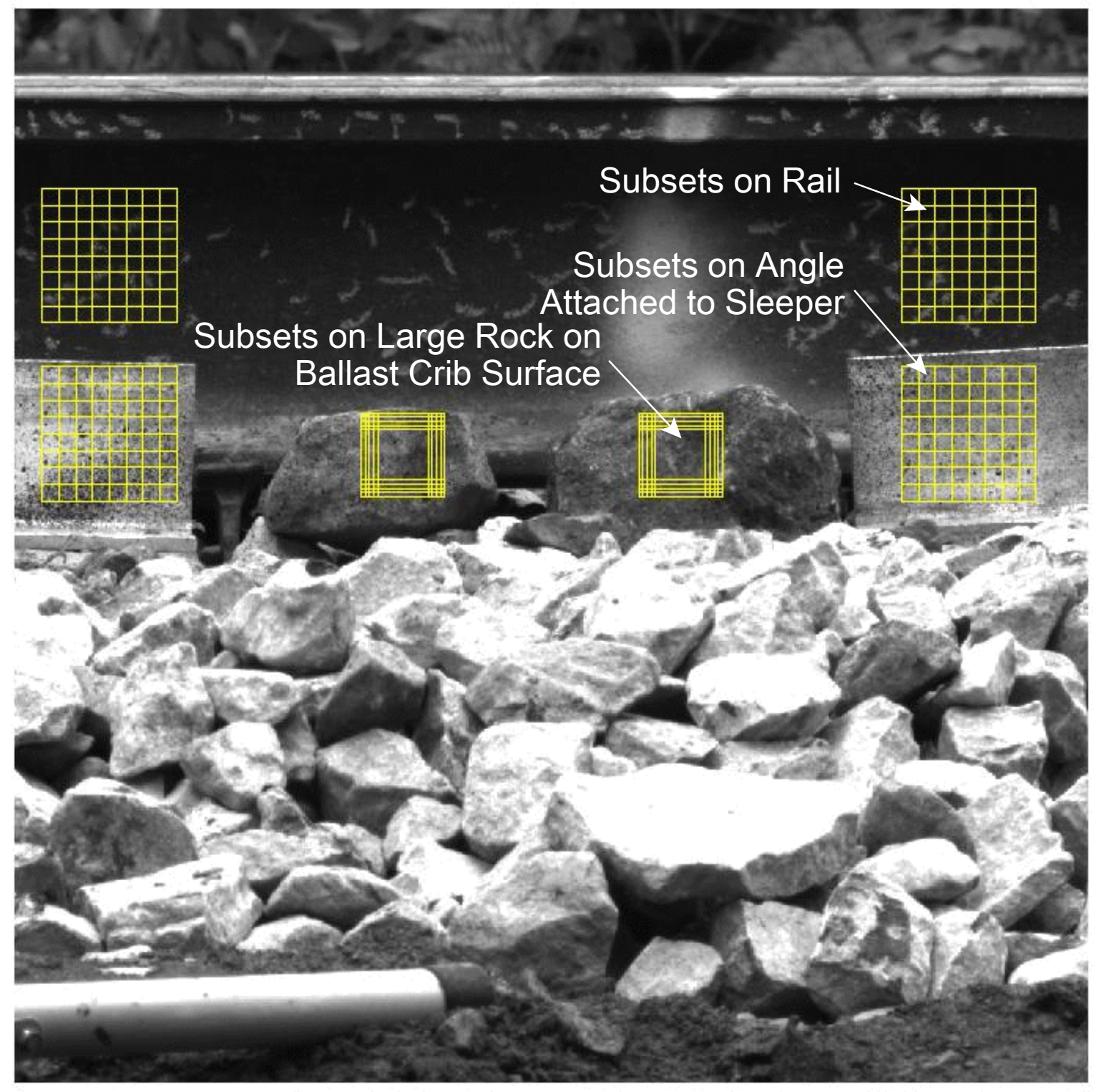

Figure 4. Example of subsets used for DIC analysis 
a)

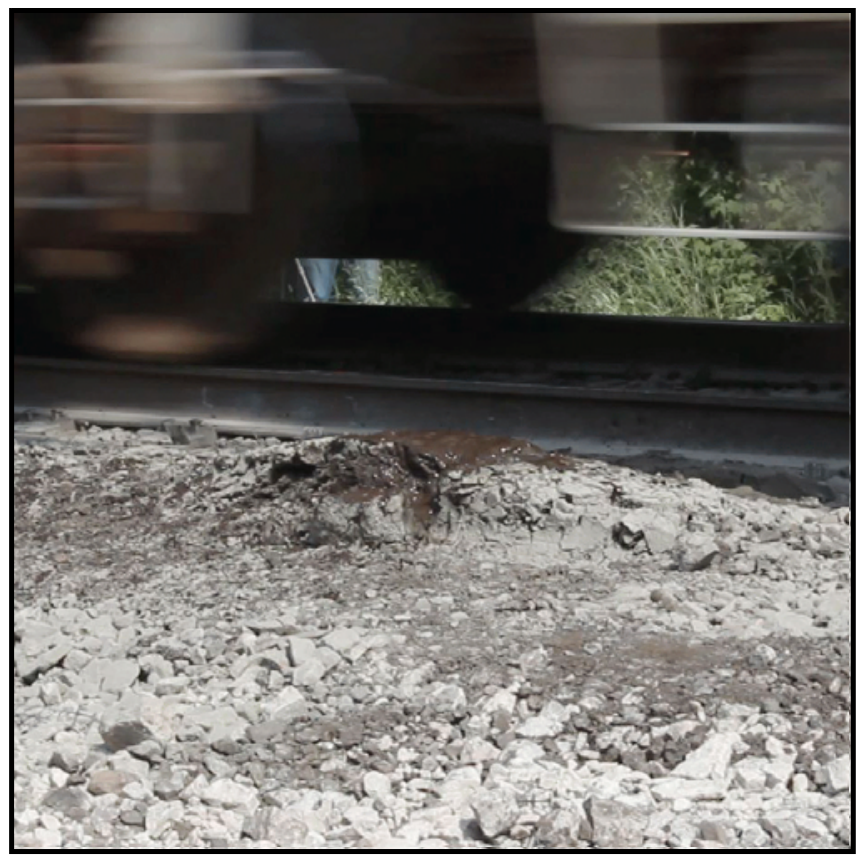

C )

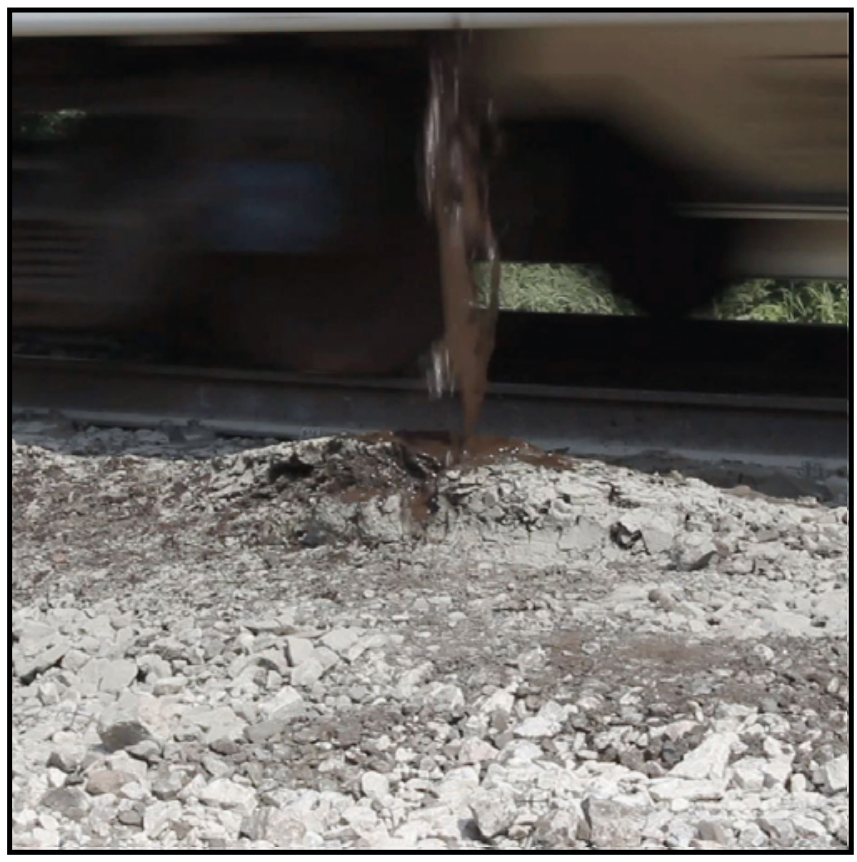

b )

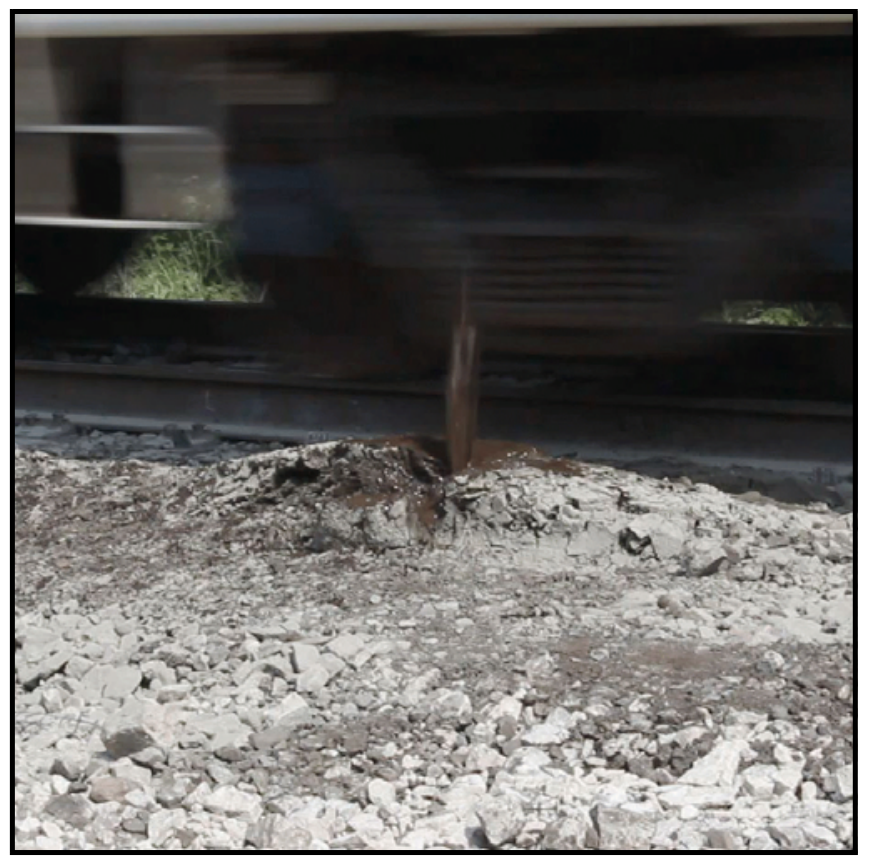

d )

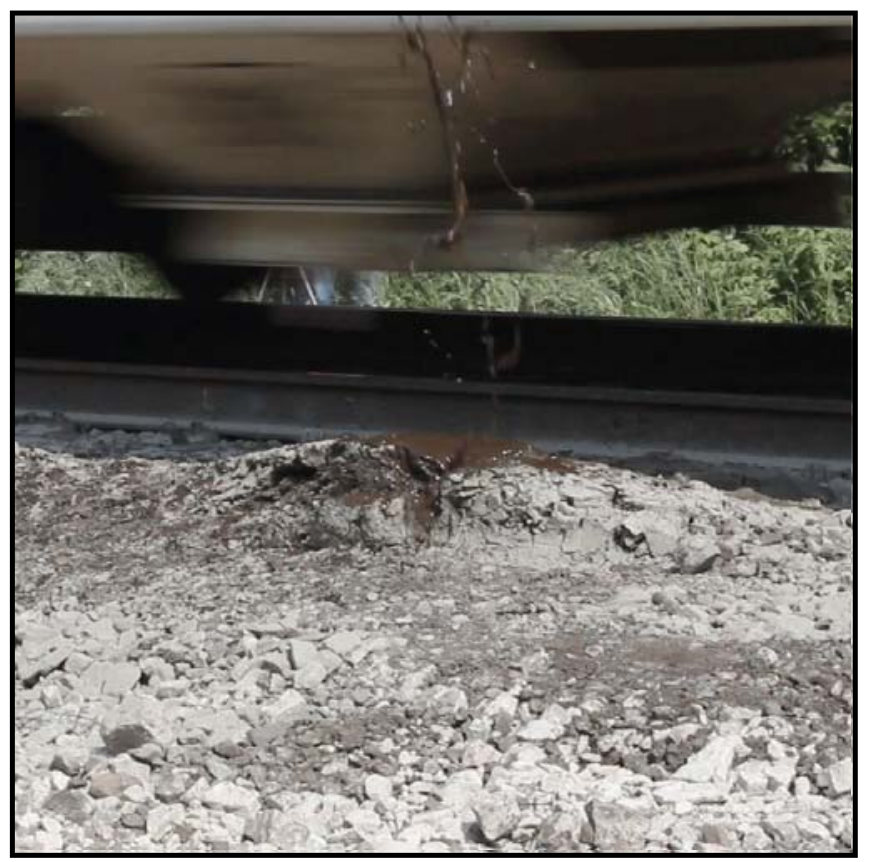

Figure 5. Image sequence illustrating the pumping and ejection of fluid and fines during the passage of a train over a period of 0.5 seconds 


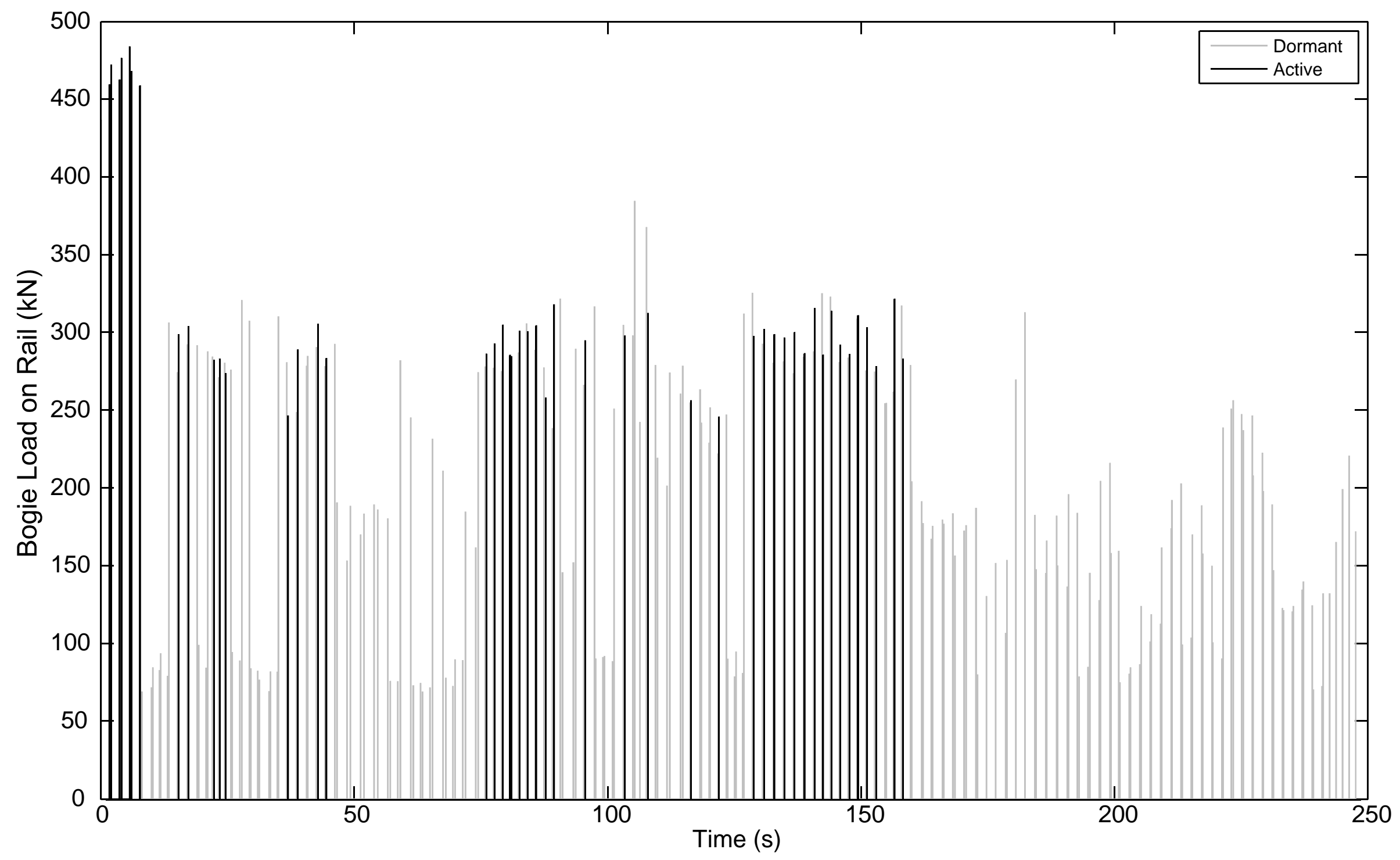

Figure 6. Bogie loads which resulted in active pumping and ejection of fluids and fines 
a )

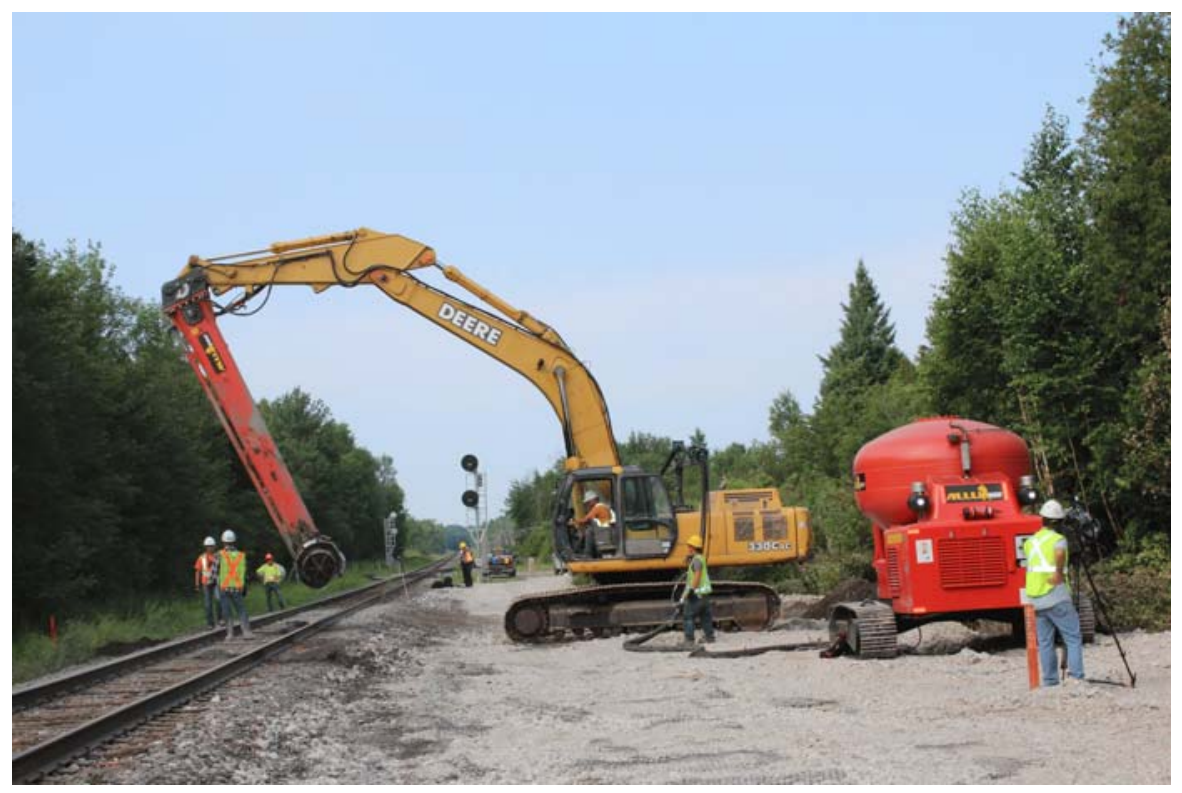

c)

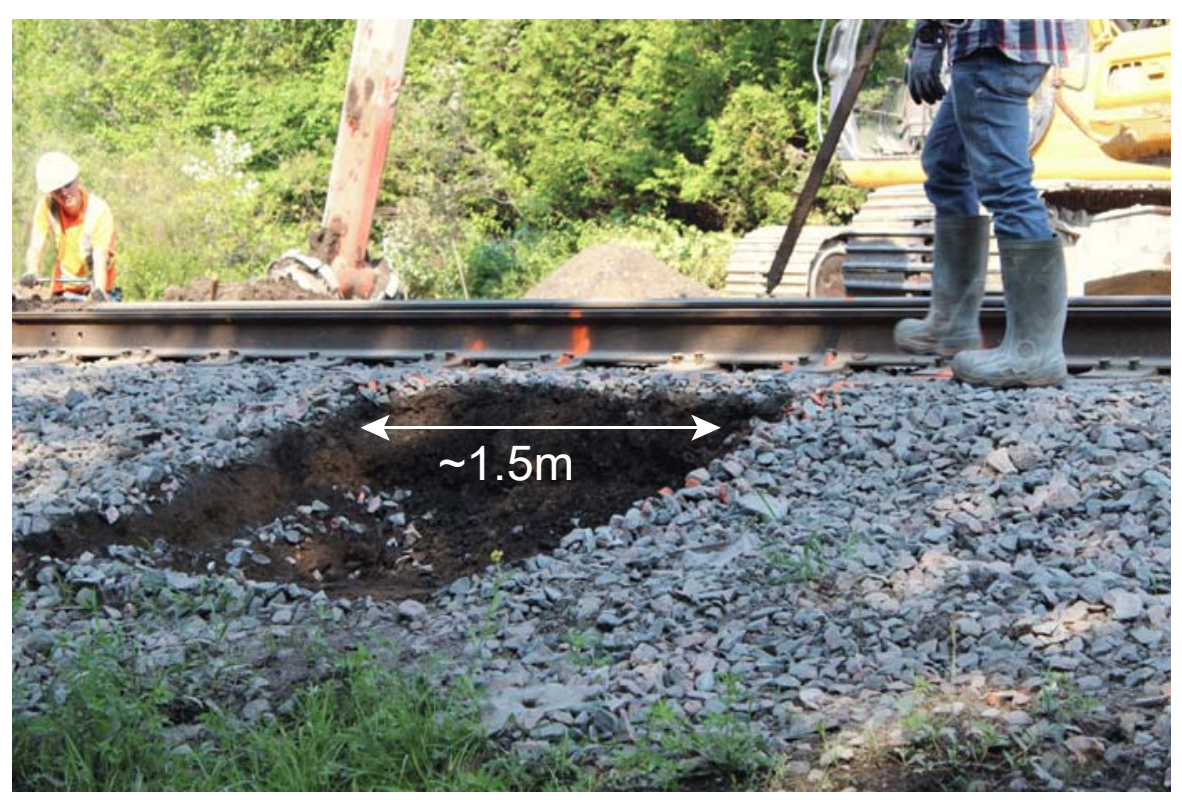

b )

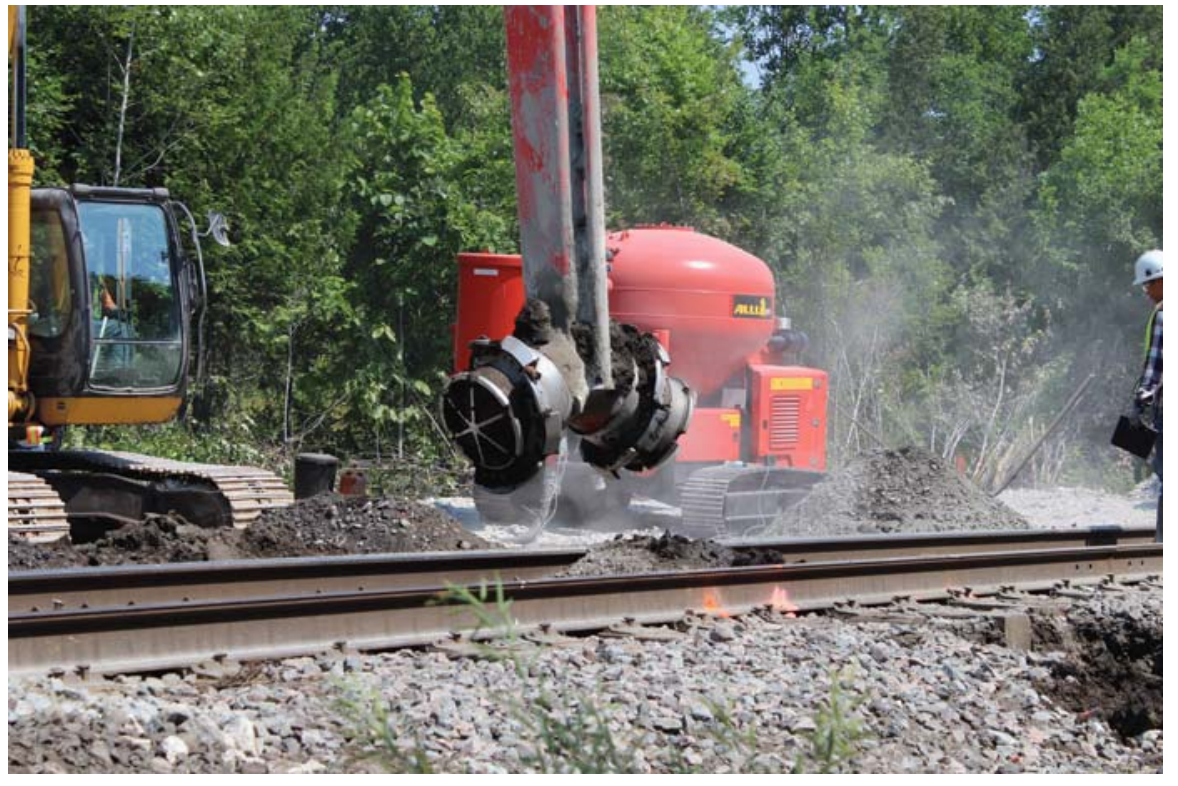

d)

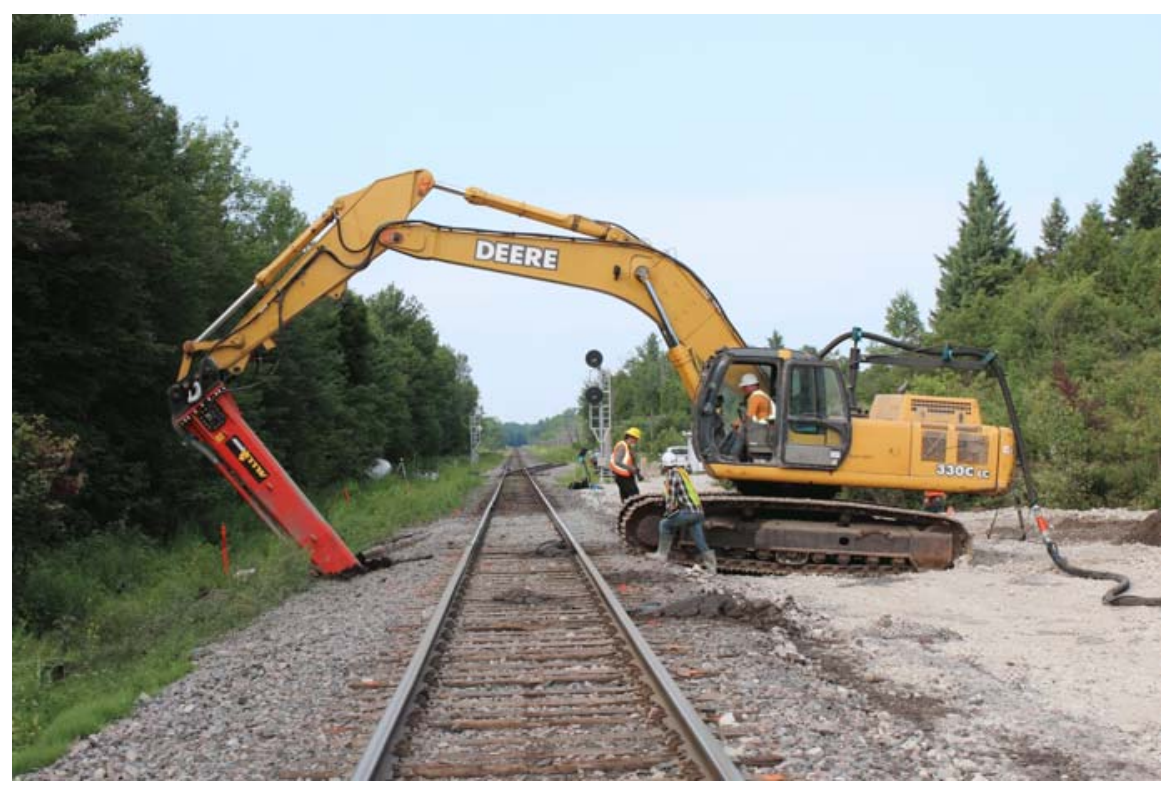

Figure 7. a ) Mass stabilization system, b ) power mixer head, c ) ballast removed for mixing, and d) mixing cement into peat subgrade 


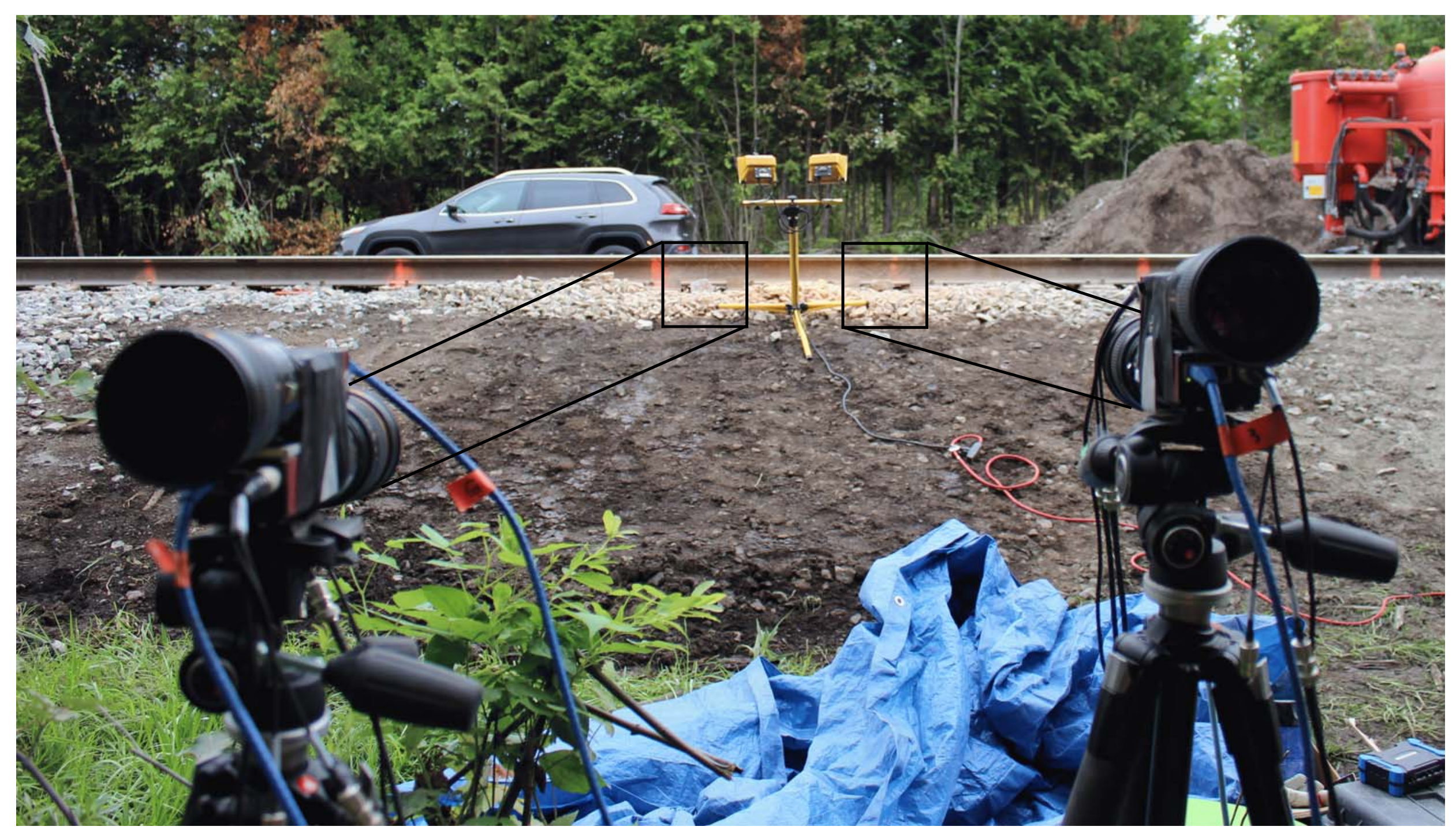

Figure 8. Camera setup 
a)

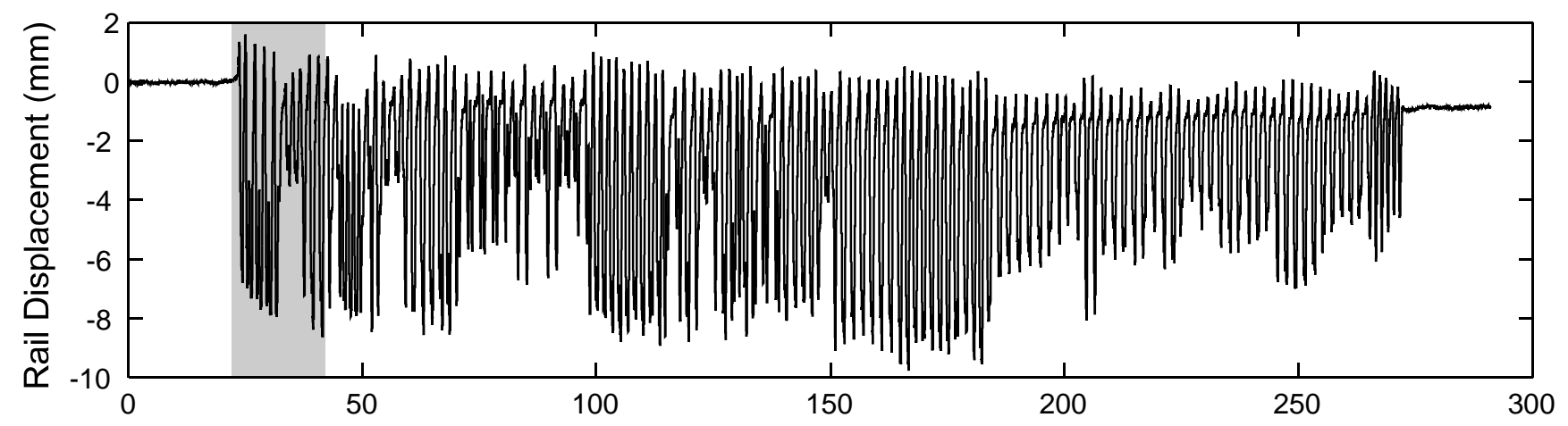

b)

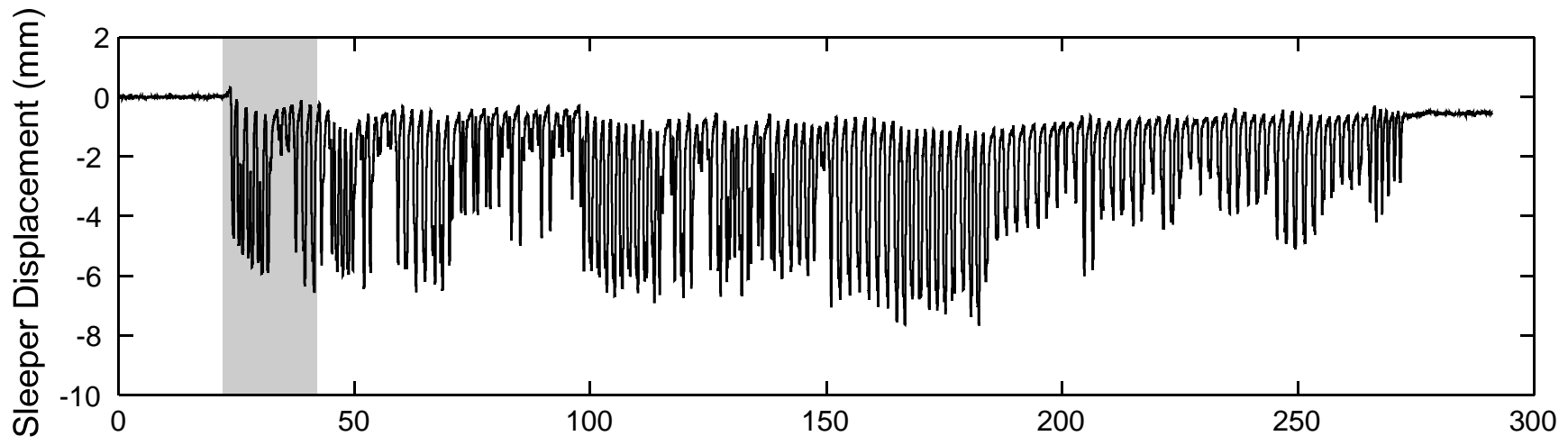

c)

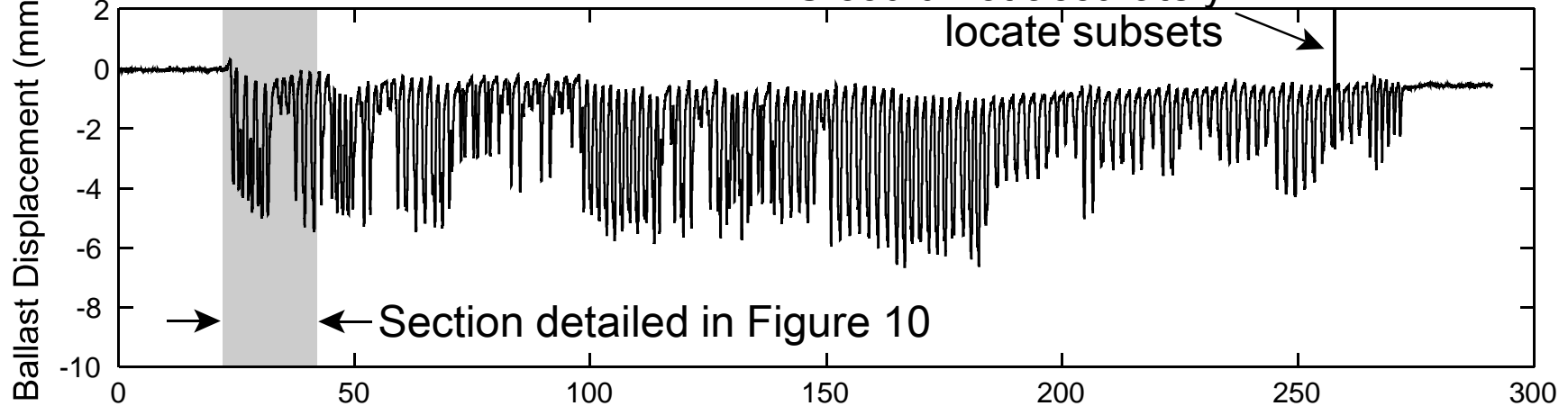

d)

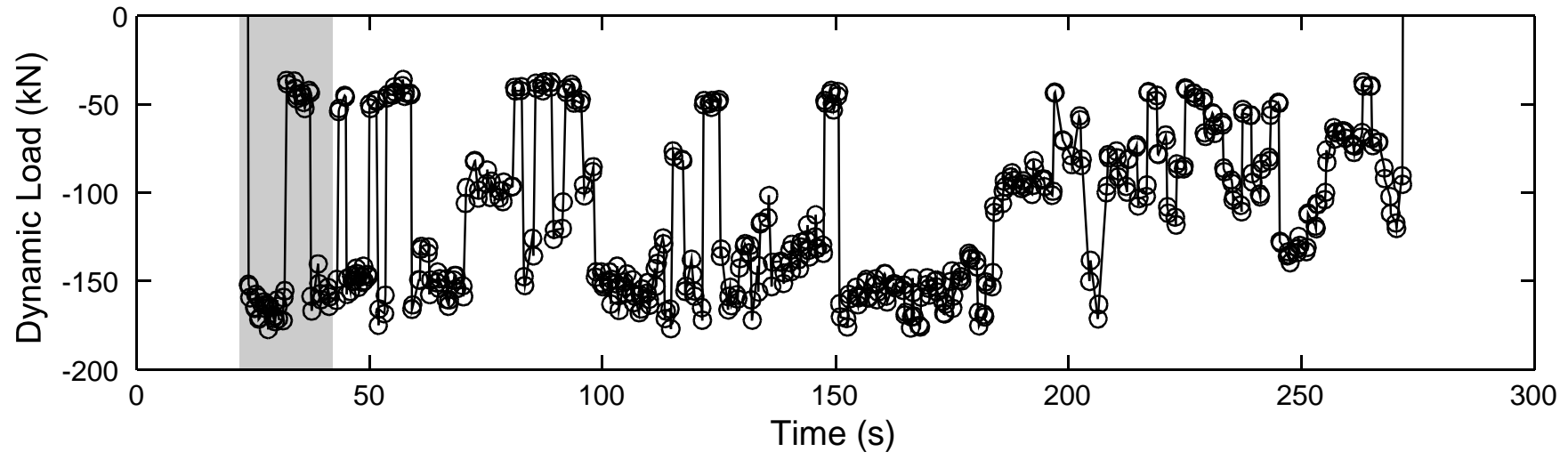

Figure 9. Vertical displacement for full train for a ) rail, b ) sleeper, c ) ballast, and d) associated wheel loads 


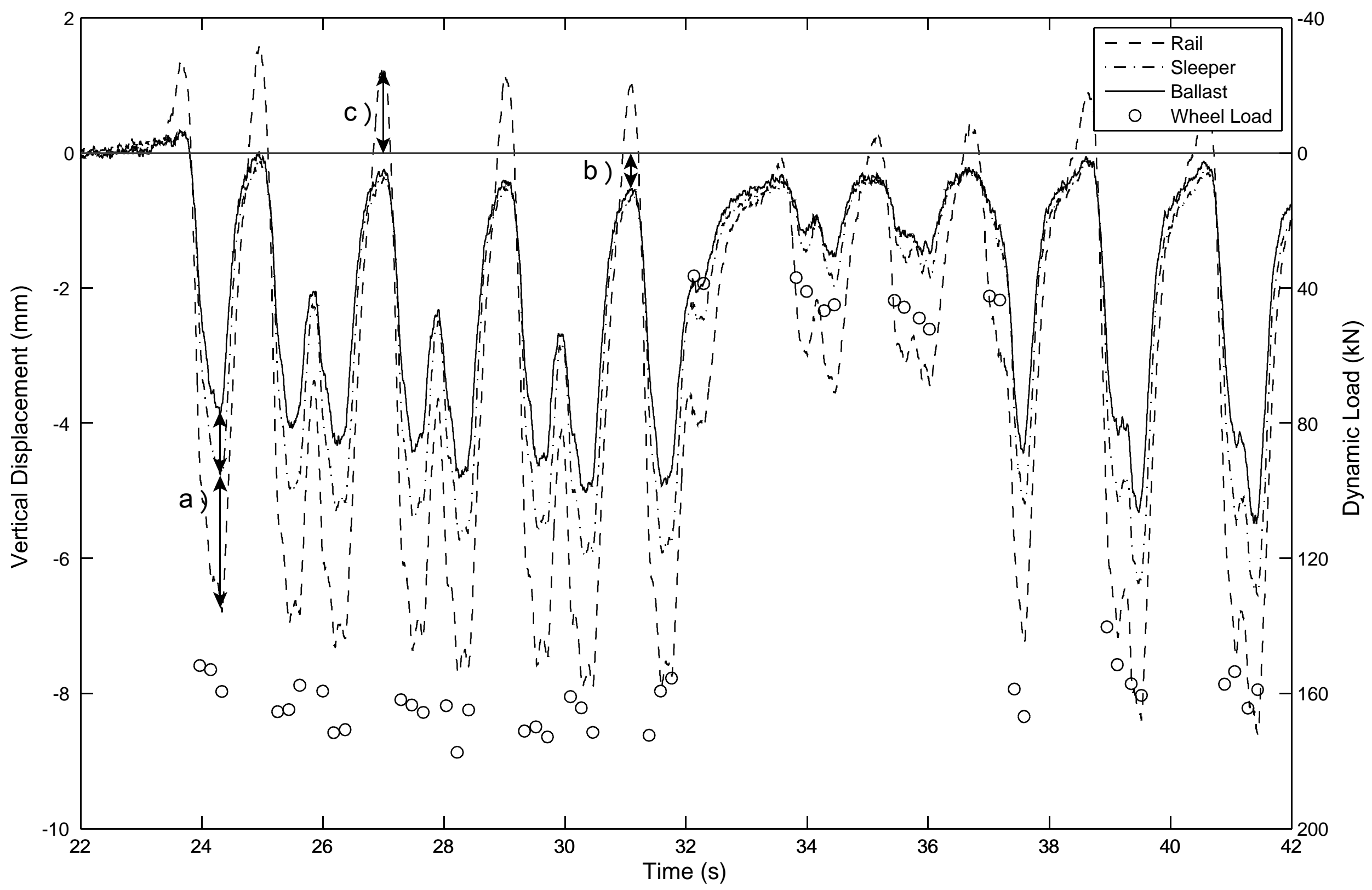

Figure 10. Rail, sleeper, and ballast crib displacements and the associated dynamic wheel loads at the beginning of a train before mass stabilization showing a ) the difference in rail, sleeper, and ballast crib displacements, b ) the sleeper and ballast crib not returning to zero displacement under rail car centres, and c ) upward rail bending 
a )

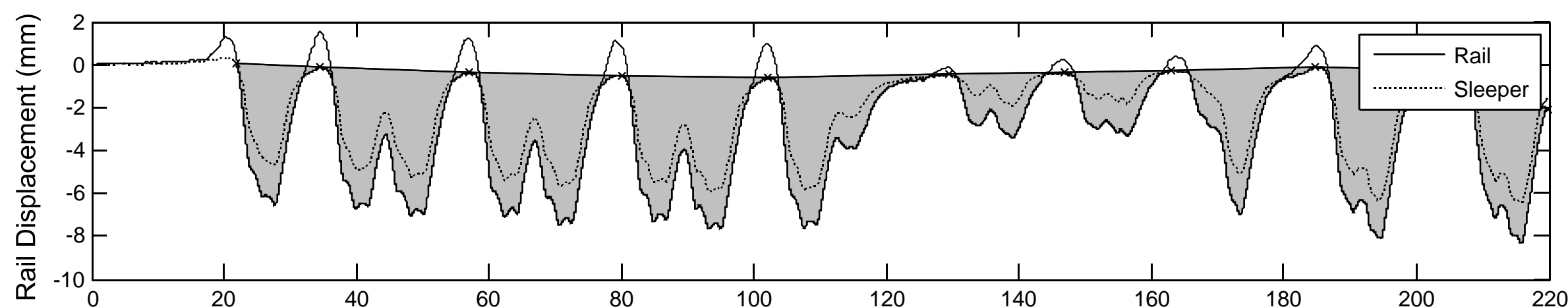

b)

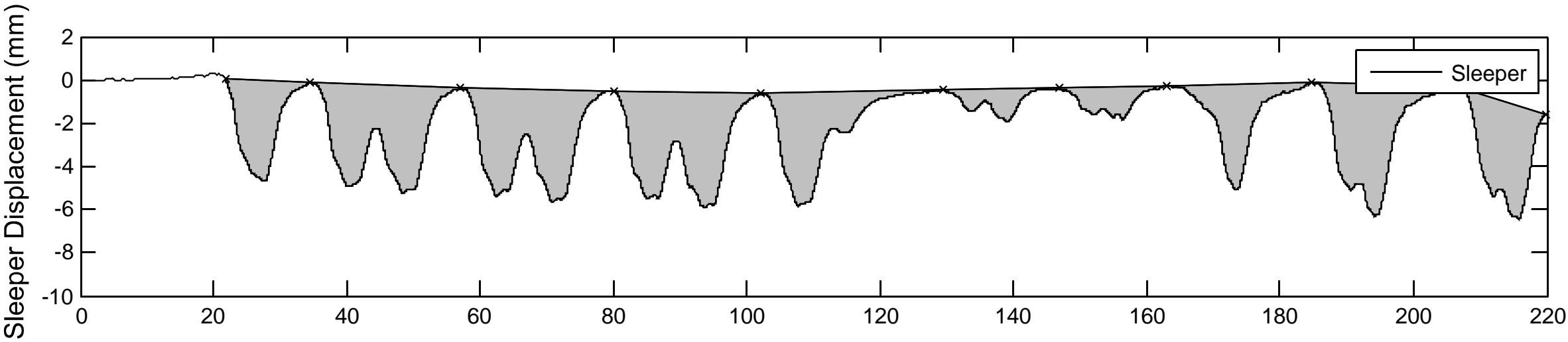

c)

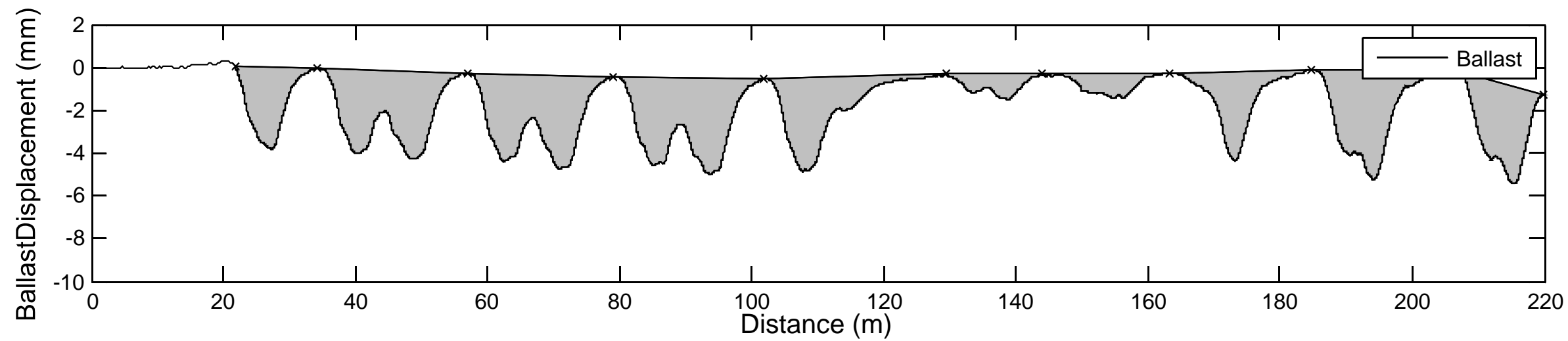

Figure 11. Sample areas used for displacement basin track modulus calculation for a ) rail , b ) sleeper, and c) ballast crib 


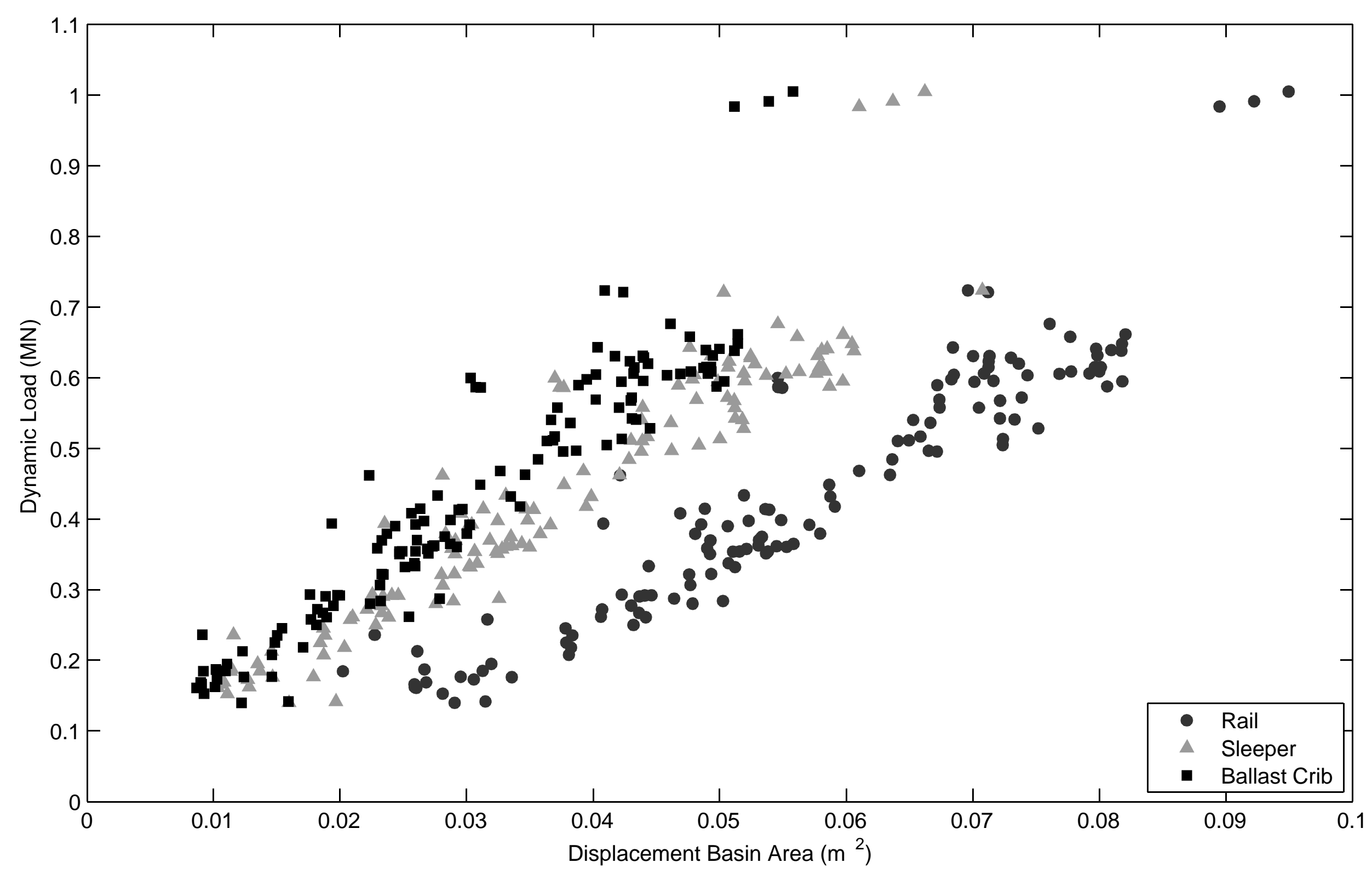

Figure 12. Displacement basin area versus dynamic load for the rail, sleeper, and ballast crib for Train 2 
a)

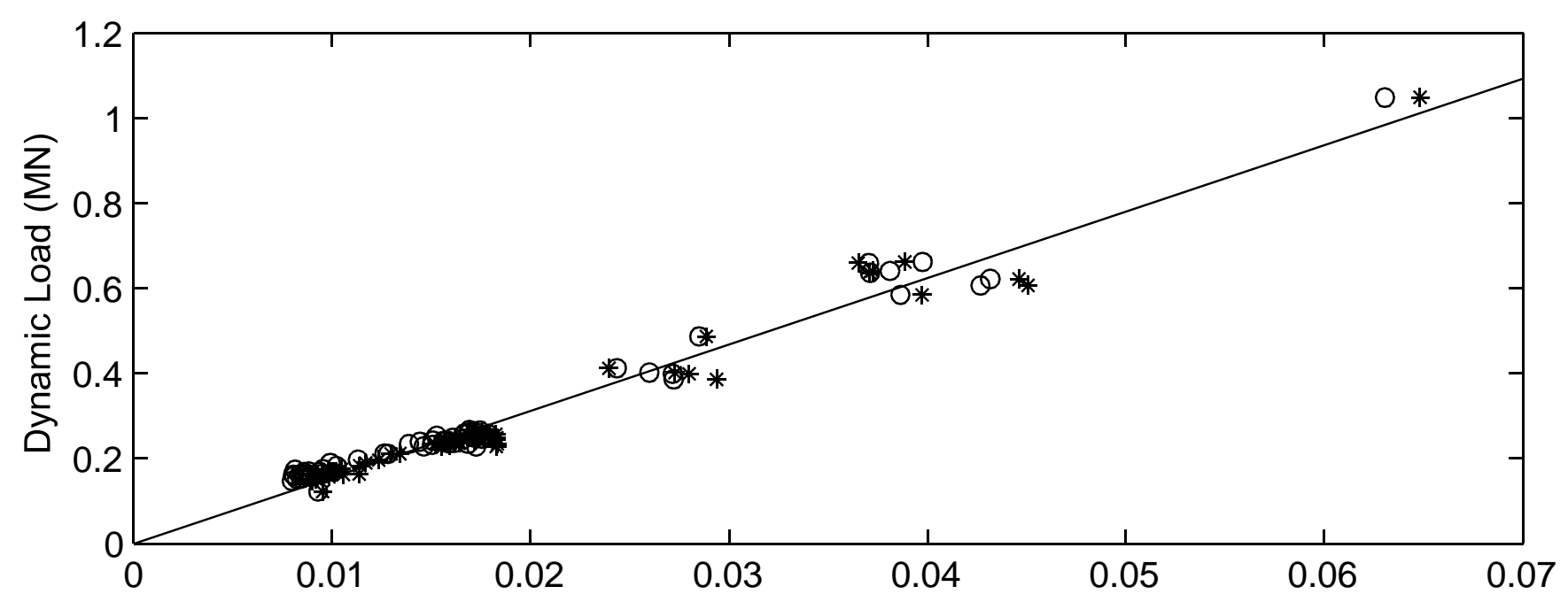

b)

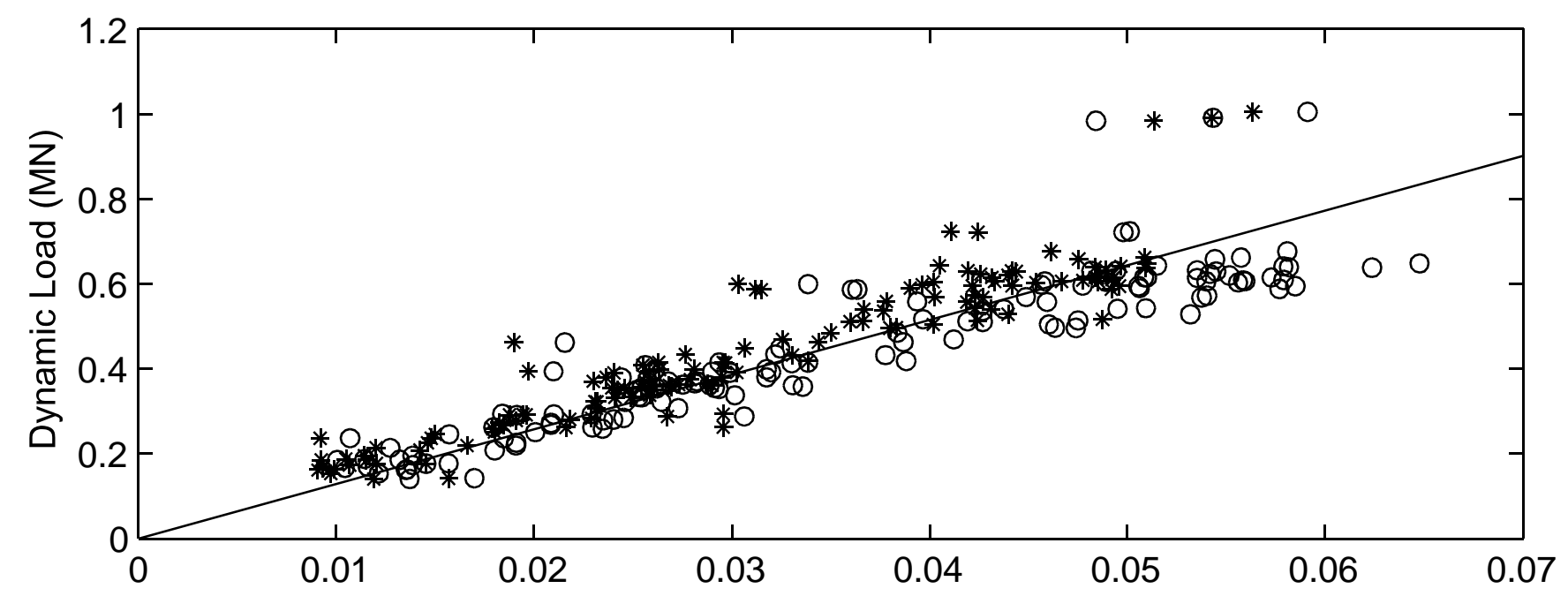

c)

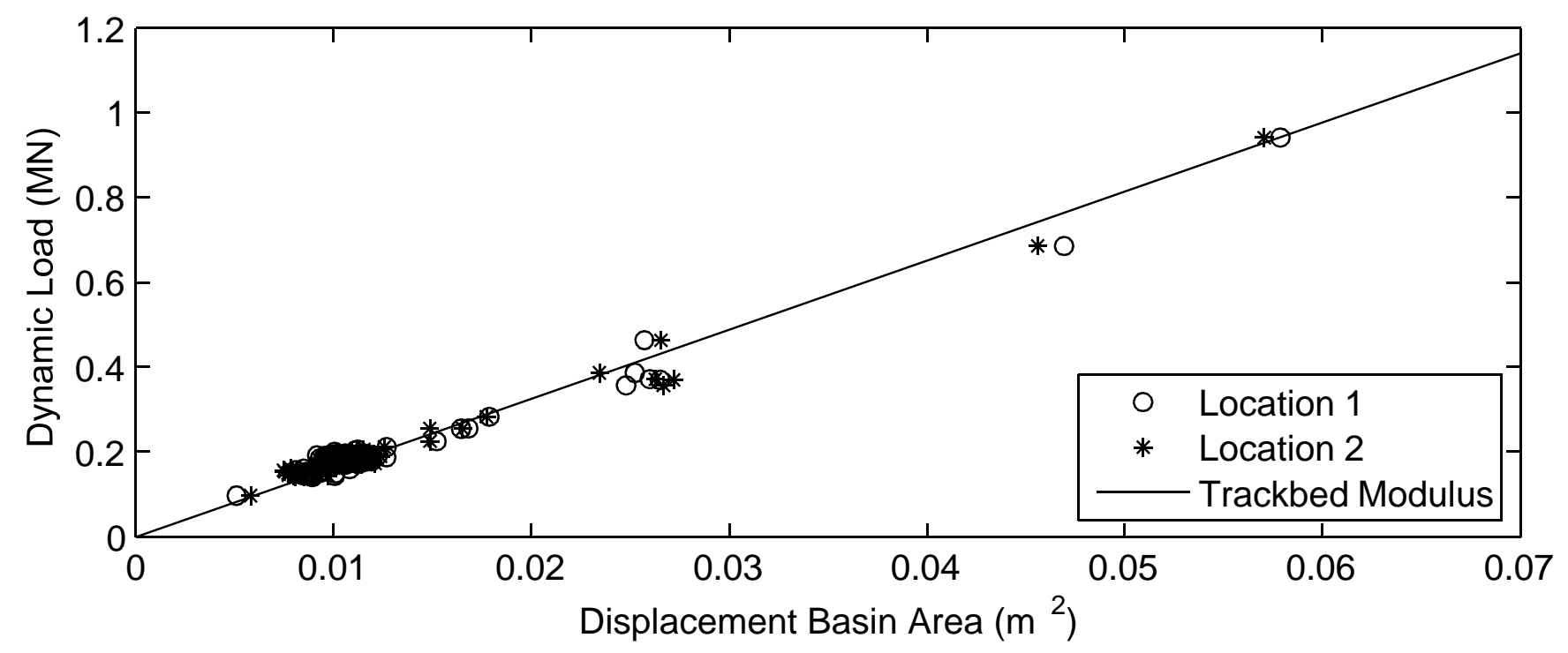

Figure 13. Pre-mass stabilization ballast crib displacement basin area versus dynamic load for a ) Train 1, b) Train 2, and c) Train 3 


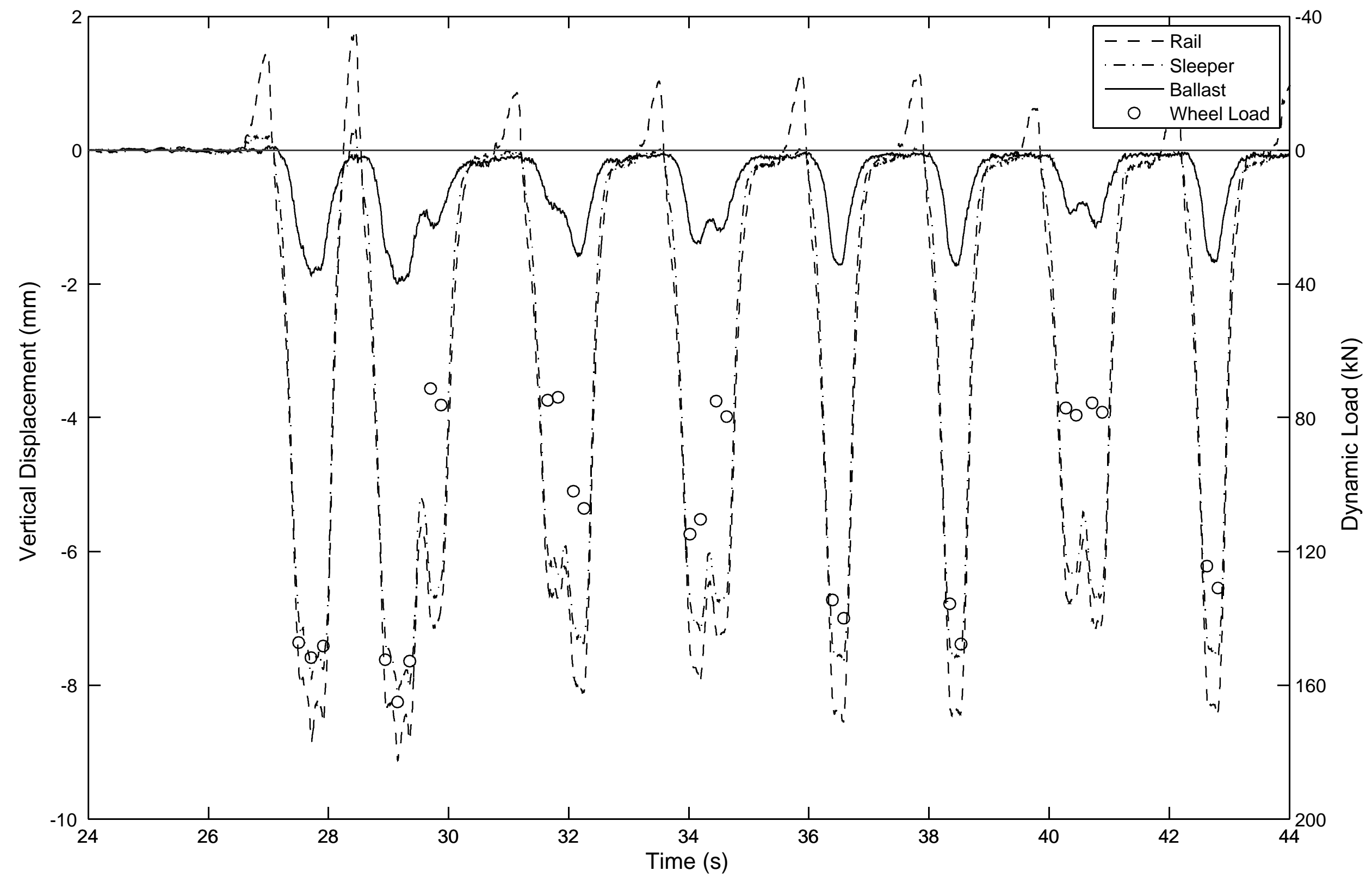

Figure 14. Rail, sleeper, and ballast crib displacements and the associated dynamic wheel loads at the beginning of a train after mass stabilization 
a)

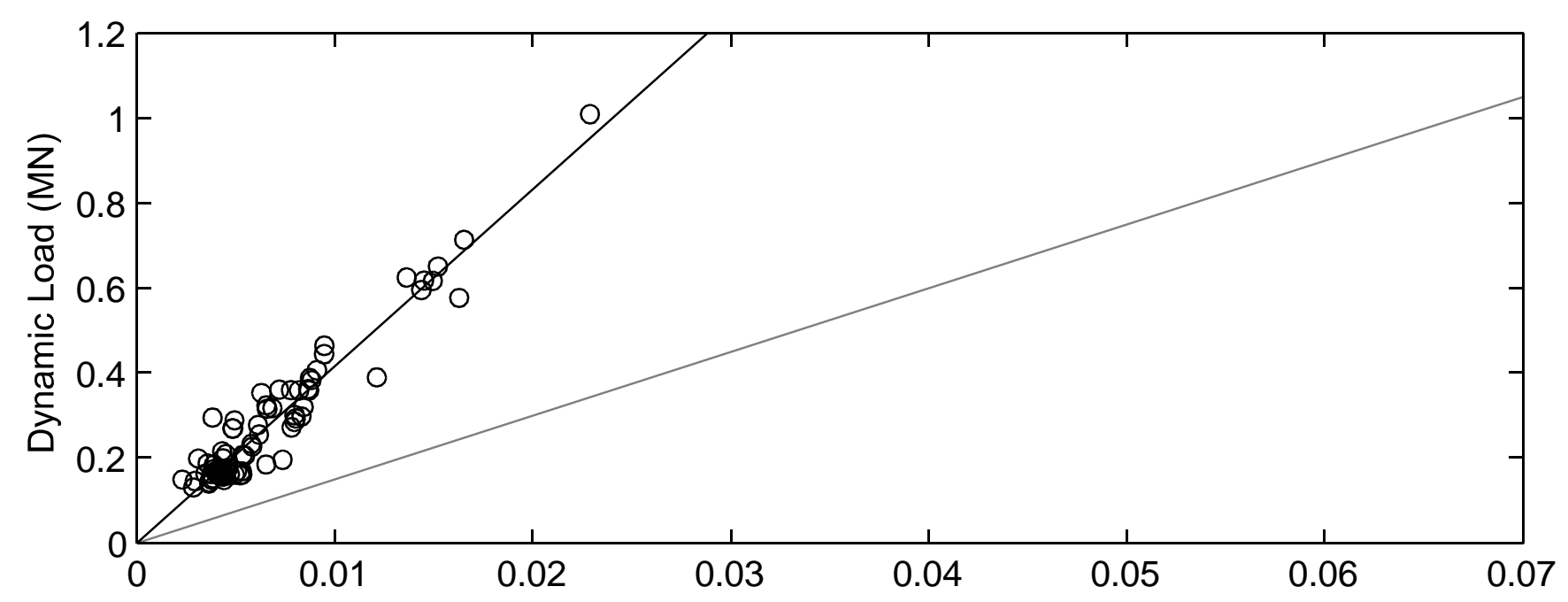

b)

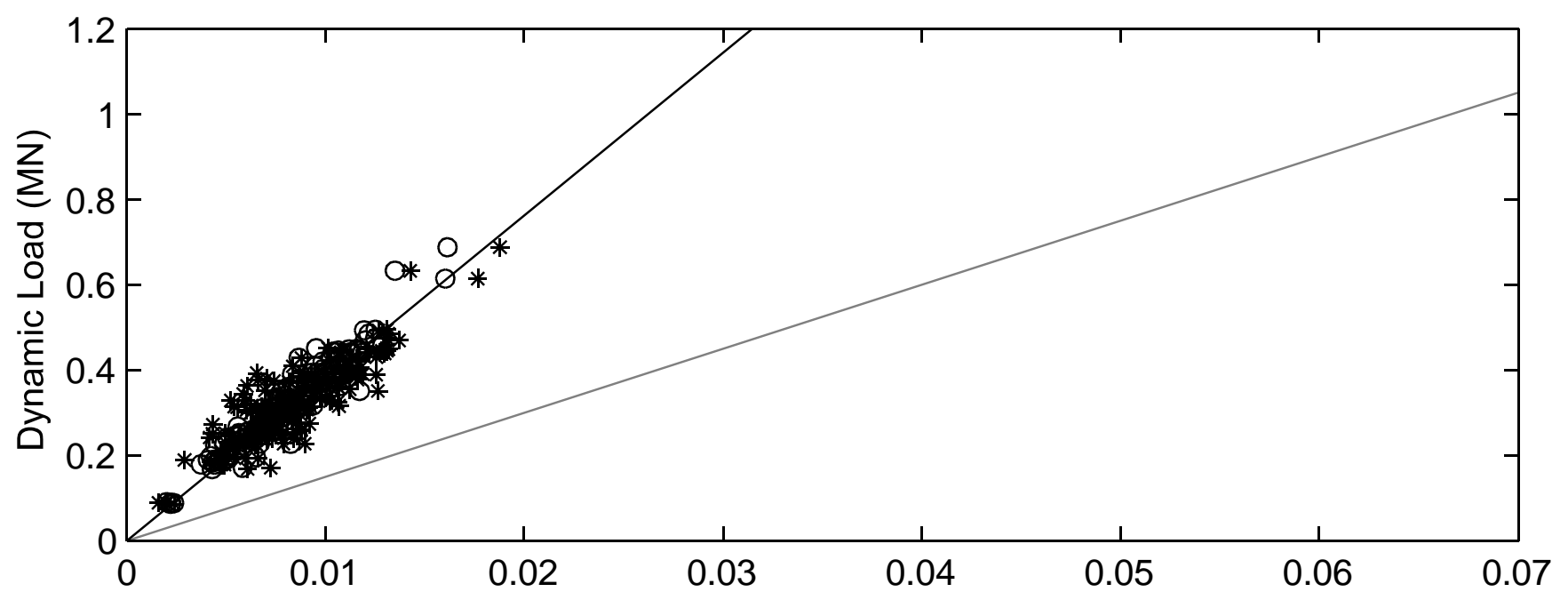

c)

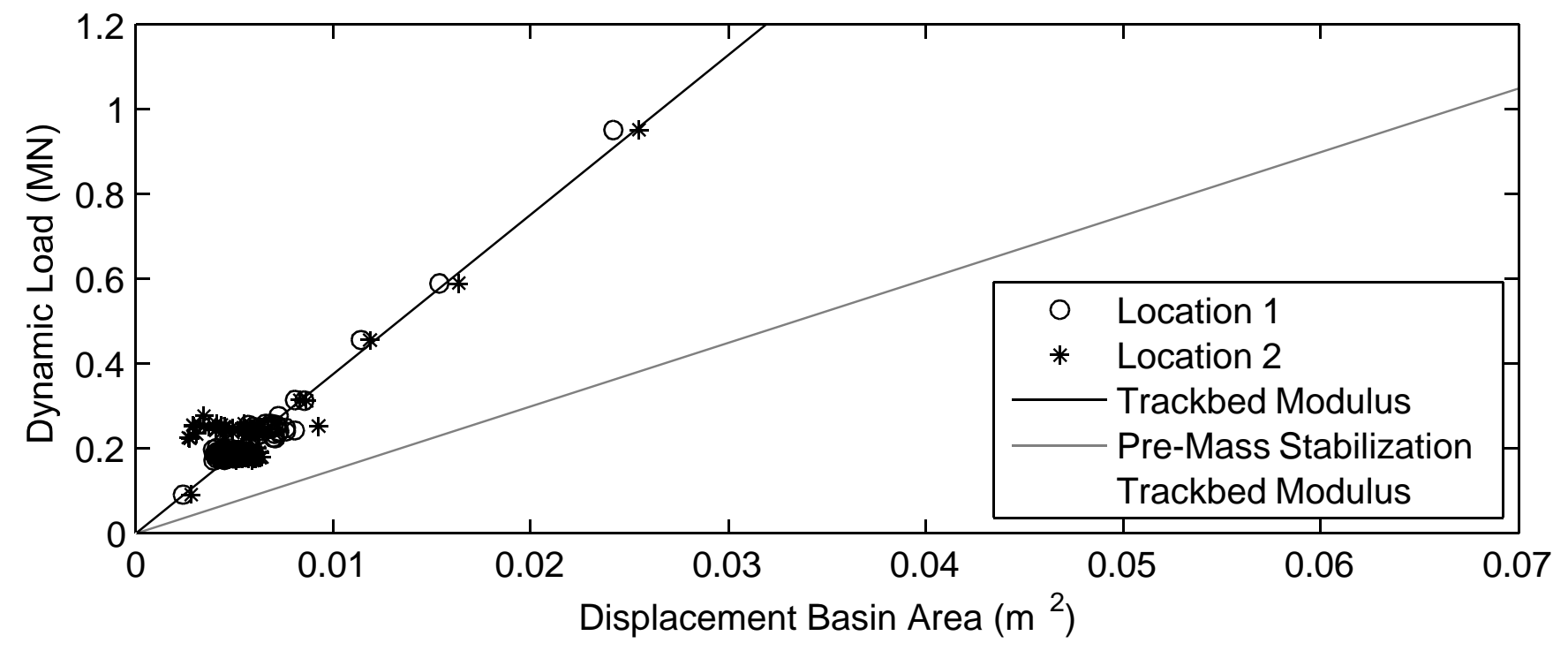

Figure 15. Post-mass stabilization ballast crib displacement basin area versus dynamic load for a ) Train 4, b ) Train 5, and c ) Train 6 


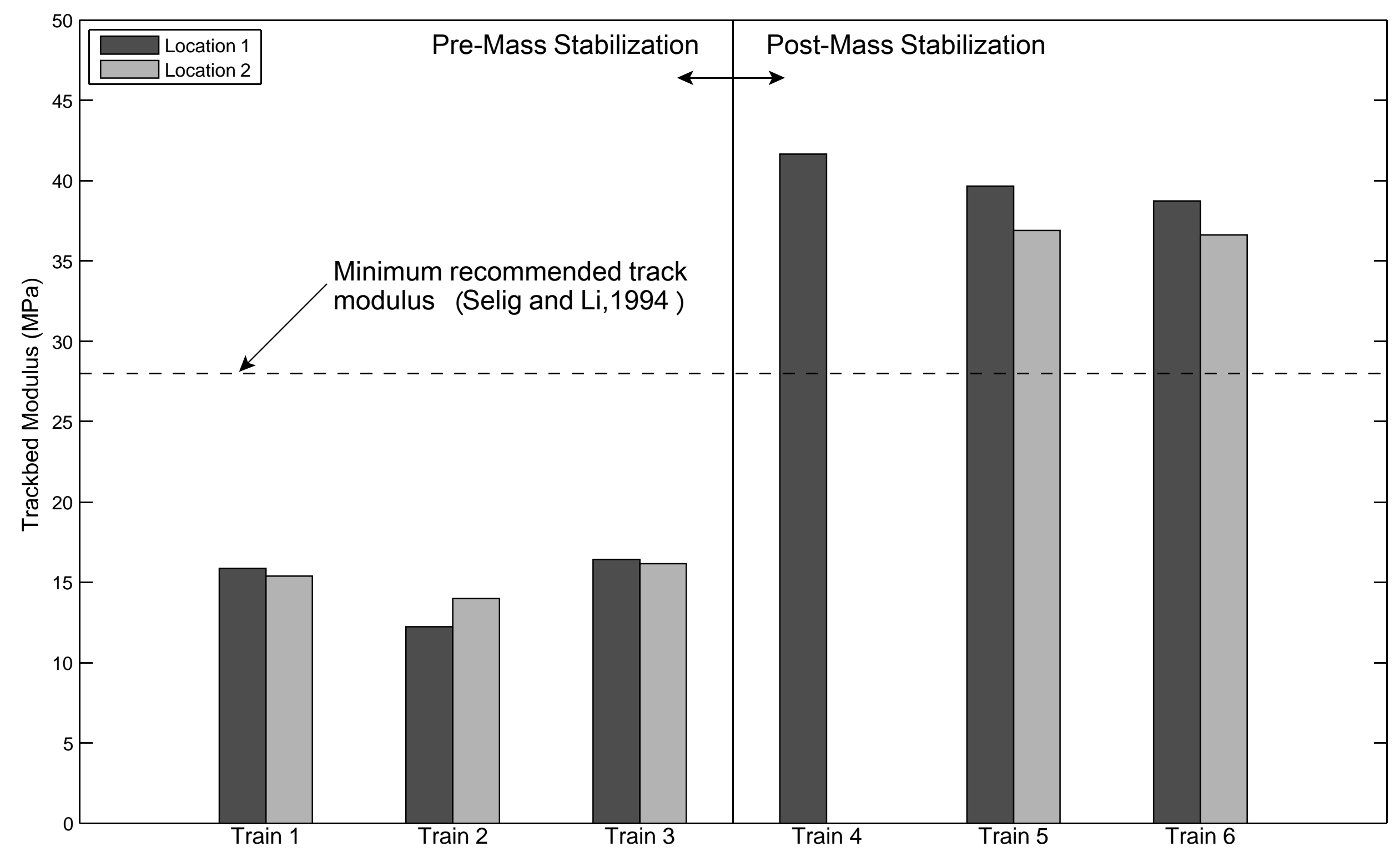

Figure 16. Comparison of trackbed modulus pre- and post-mass stabilization 